\title{
Nse5/6 inhibits the Smc5/6 ATPase to facilitate DNA substrate selection
}

\author{
Michael Taschner ${ }^{1}$, Jérôme Basquin ${ }^{2, \#}$, Barbara Steigenberger ${ }^{2,3,4, \#}$, Ingmar Schaefer², Young-Min Soh", \\ Claire Basquin², Esben Lorentzen ${ }^{5}$, Markus Räschle ${ }^{6}$, Richard A. Scheltema ${ }^{3,4}$, Stephan Gruber ${ }^{1,{ }^{*}}$
}

\begin{abstract}
Eukaryotic cells employ three SMC complexes to control DNA folding and topology. The Smc5/6 complex plays roles in DNA repair and in preventing the accumulation of deleterious DNA junctions. To elucidate how specific features of Smc5/6 govern these functions, we reconstituted the yeast holo-complex. We found that the Nse5/6 sub-complex strongly inhibited the Smc5/6 ATPase by preventing productive ATP binding. This inhibition was relieved by plasmid DNA binding but not by short linear DNA, while opposing effects were observed without Nse5/6. We uncovered two binding sites for Nse5/6 on Smc5/6, based on an Nse5/6 crystal structure and cross-linking mass spectrometry data. One binding site is located at the Smc5/6 arms and one at the heads, the latter likely exerting inhibitory effects on ATP hydrolysis. Cysteine cross-linking demonstrated that the interaction with Nse5/6 anchored the ATPase domains in a non-productive state, which was destabilized by ATP and DNA. Under similar conditions, the Nse4/3/1 module detached from the ATPase. Altogether, we show how DNA substrate selection is modulated by direct inhibition of the Smc5/6 ATPase by Nse5/6.

\section{Keywords}

Smc5, Smc6, genome maintenance, chromosome segregation, SMC, ATPase, loop extrusion, cohesin, condensin

${ }^{1}$ Department of Fundamental Microbiology (DMF), Faculty of Biology and Medicine (FBM), University of Lausanne (UNIL), Lausanne, Switzerland

${ }^{2}$ Max Planck Institute of Biochemistry, Martinsried, Germany

${ }^{3}$ Biomolecular Mass Spectrometry and Proteomics, Bijvoet Center for Biomolecular Research and Utrecht Institute for Pharmaceutical Sciences, Utrecht University, Utrecht, The Netherlands

${ }^{4}$ Netherlands Proteomics Centre, Utrecht, The Netherlands

${ }^{5}$ Department of Molecular Biology and Genetics, Aarhus University, Aarhus, Denmark

${ }^{6}$ Molecular Genetics, University of Kaiserslautern, Kaiserslautern, Germany

\# These authors contributed equally to the work

*Corresponding author: stephan.gruber@unil.ch
\end{abstract}

Maintenance of chromosome structure and the faithful transmission of genetic information are essential processes in all domains of life orchestrated by the widely conserved Structural Maintenance of Chromosomes (SMC) complexes [reviewed in (Yatskevich et al., 2019)]. The main function of these ATP-powered DNA-folding machines in bacteria is to prevent entanglement of newly replicated chromosomes to ensure their unperturbed segregation to daughter cells. Eukaryotic cells also need to prevent such entanglements during cell division, but additionally efficient sister chromatid cohesion, chromosome condensation, as well as chromosome individualization needs to be ensured. Three distinct eukaryotic SMC complexes (cohesin, condensin, and Smc5/6) divide these tasks between them. Cohesin folds interphase chromosomes into defined domains to regulate gene expression (Szabo et al., 2019) and participates in DNA repair by homologous recombination (Litwin et al., 2018). It also holds sister chromatids together between S-phase and the onset of anaphase (Yatskevich et al., 2019). Condensin compacts and structures chromosomes in mitosis to promote sister chromatid resolution and disjunction in prometaphase and anaphase, respectively (Hirano, 2016). The molecular functions of the Smc5/6 complex are understood in less detail (Aragon, 2018). Several Smc5/6 genes were first identified in screens for DNA damage-sensitive mutants (Lehmann et al., 1995; McDon- ald et al., 2003; Onoda et al., 2004; Prakash and Prakash, 1977; Torres-Rosell et al., 2005a; Torres-Rosell et al., 2005b). Complete Smc5/6 loss-of-function leads to cell death associated with severe chromosome segregation defects during both mitotic and meiotic cell divisions (Copsey et al., 2013; McDonald et al., 2003; Pebernard et al., 2004; Xaver et al., 2013). Without Smc5/6, certain toxic DNA structures such as unresolved recombination intermediates, DNA intertwinings, or incompletely replicated chromosomal regions prevent proper chromosome segregation (Kegel et al., 2011; Torres-Rosell et al., 2005b; Torres-Rosell et al., 2007), especially at repeated DNA sequences such as the ribosomal DNA arrays (Peng et al., 2018). It is however unclear if Smc5/6 prevents their formation or promotes their removal.

At their core all SMC complexes have a dimer of SMC proteins, each of which contains a 'hinge' domain that mediates SMC dimerization and connects via a long $(35-50 \mathrm{~nm})$ antiparallel coiled-coil 'arm' to a globular ABC-type 'head' domain with highly conserved motifs for ATP-binding and hydrolysis (Hirano et al., 2001; Hopfner, 2016; Lammens et al., 2004). Two ATP molecules are sandwiched by residues of the Walker A and B motifs of one SMC subunit and the signature motif of the other SMC subunit. ATP hydrolysis by the SMC heads is essential for the function of all SMC complexes, 


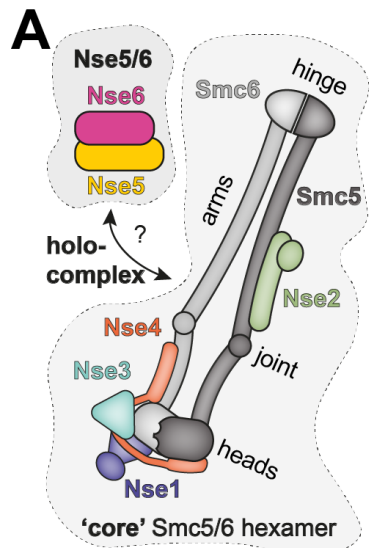

C

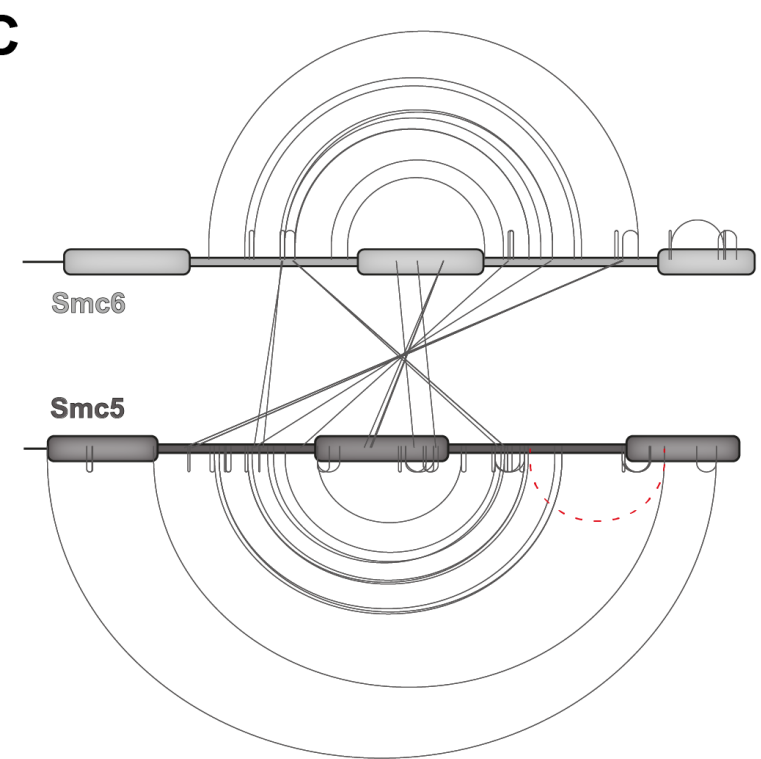

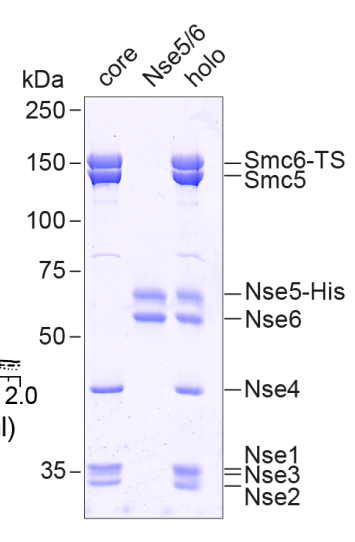
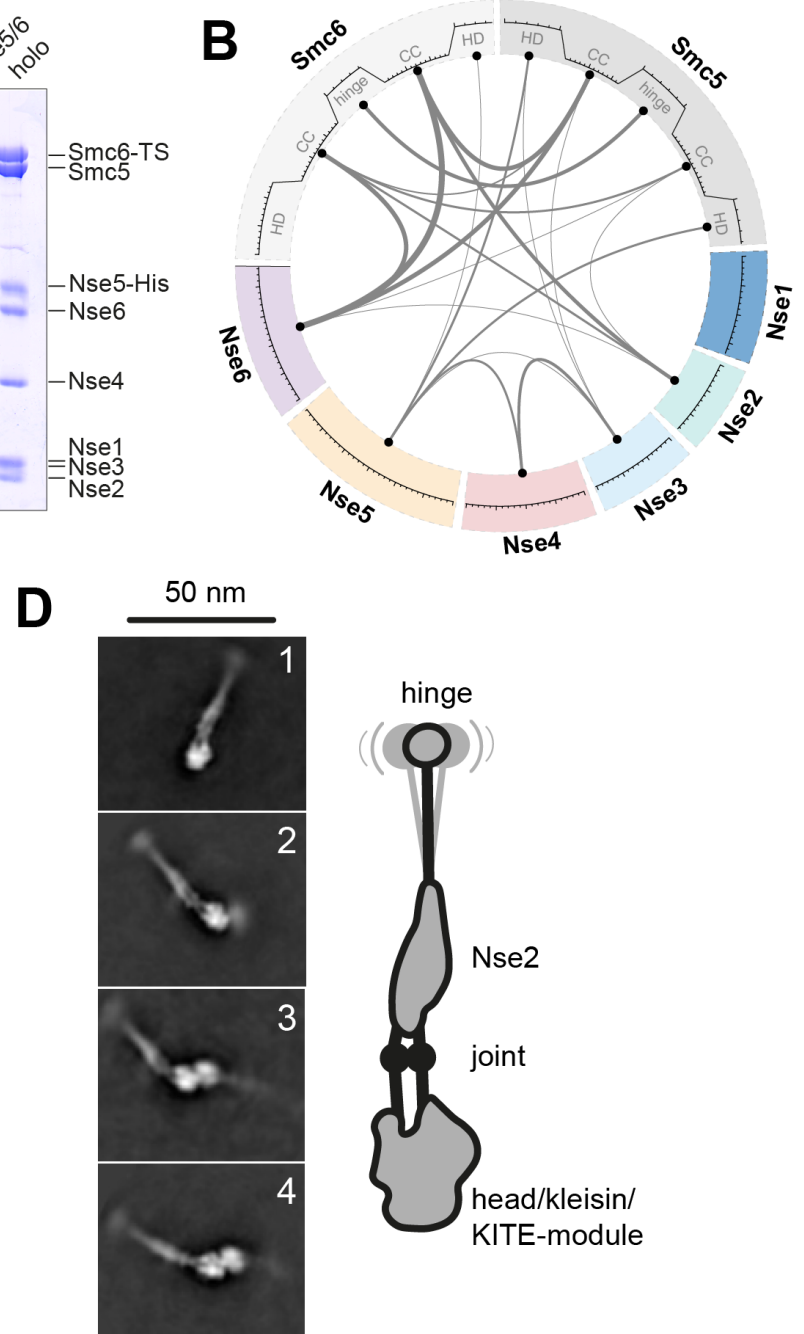

Figure 1. Molecular architecture of yeast Smc5/6 complexes determined by cross-linking massspectrometry (XL-MS) and cryo-electron microscopy (cryo-EM). A. Left panel, schematic depiction of the composition and organization of the yeast Smc5/6 'core' hexamer and the Nse5/6 dimer. Middle panel, elution profiles for analytical gel filtration runs of the Smc5/6 core hexamer. Right panel, peak fractions analysis. B. Representation of lysine-lysine inter-subunit cross-links identified by XL-MS. For simplicity cross-links between proteins (or domains) are grouped, and the thickness of the lines indicate the total number of crosslinks. C. Cross-links obtained within and between Smc5 and Smc6 subunits of the Smc5/6 octamer (dashed line in red colours potential false positive). D. Selected 2D class averages obtained by cryo-electron microscopy of the yeast Smc5/6 hexamer. Representative classes with dimers of Smc5/6 hexamers are displayed (bottom images). Emerging details are indicated schematically (right panel).

but is rather slow (mostly $i 1 \mathrm{ATP} / \mathrm{s}$ ) compared to other ATPases. It is however stimulated in the presence of DNA substrates (Hassler et al., 2018). The ATP hydrolysis cycle involves major structural rearrangements within the SMC dimers, which have been delineated only in some detail for example for the prokaryotic Smc-ScpAB complex (Chapard et al., 2019; Diebold-Durand et al., 2017; Soh et al., 2015; Vazquez Nunez et al., 2019). Briefly, in the absence of ATP the two SMC proteins are in a 'juxtaposed' J-state with closely aligned arms and a clear rod-shaped appearance in electron micrographs (refs and/or Fig. 1D?). The heads contact each other close to their signature motifs to form a structure that is incompatible with ATP hydrolysis. In the presence of ATP, the head domains rearrange to adopt the 'ATP-engaged' E-state with sandwiched ATP molecules (Diebold-Durand et al., 2017; Lammens et al., 2004). This conformation is incompatible with the rod conformation. At the least, it opens the arms in the head-proximal area, yielding a more open ring-like complex that has been observed for cohesin by cryo-EM (Higashi et al., 2020; Shi et al., 2020) and characterized in Smc-ScpAB by electron paramagnetic resonance and cross-linking (Etheridge et al., 2020; Nunez et al., 2021). Upon ATP hydrolysis the heads disengage, the coiled-coils zip back up, and the complex reverts back into the J-state. The presence of DNA presumably assists the complex with these structural transitions, leading to a positive effect on the ATP hydrolysis rate. Indeed, DNA binding sites on top of the engaged heads were described for several related complexes (Higashi et al., 2020; Liu et al., 2016; Seifert et al., 2016; Shi et al., 2020; Vazquez Nunez et al., 2019).

Another invariably conserved subunit, called 'kleisin', asymmetrically bridges the two SMC proteins at their head domains to create a tripartite ring structure capable of entrapping DNA in its lumen 
(Burmann et al., 2013; Gligoris et al., 2014; Haering et al., 2004; Palecek et al., 2006; Wilhelm et al., 2015). Kleisin also serves as an attachment point for additional proteins from the KITE (KleisinInteracting Tandem winged-helix Element) or HAWK (HEAT-protein Associated With Kleisin) families (Palecek and Gruber, 2015; Wells et al., 2017) for which functions related to DNA substrate interactions and ATPase regulation are emerging (Kschonsak et al., 2017; Li et al., 2018; Vondrova et al., 2020; Zabrady et al., 2016).

A fully assembled SMC complex utilizes the energy released by ATP hydrolysis in two manners: (1) 'Topological entrapment' of DNA molecules inside the tripartite SMC/kleisin ring after regulated opening of (an) entry/exit gate(s) is the main mechanism by which cohesin holds sister chromatids together (Gligoris et al., 2014). Similar activities have also been described for condensin (Cuylen et al., 2011; Cuylen et al., 2013), Smc5/6 (Gutierrez-Escribano et al., 2020; Kanno et al., 2015), and prokaryotic Smc-ScpAB (Wilhelm et al., 2015), albeit in less mechanistic detail. (2) 'Loop extrusion' refers to an active ATP-dependent DNA-folding process and is used by condensin to compact mitotic chromatids and by cohesin to shape interphase chromosomes (Yatskevich et al., 2019). Such a biochemical activity has so far been reconstituted in vitro for cohesin and condensin (Davidson et al., 2019; Ganji et al., 2018; Kim et al., 2019) but it may well be a conserved feature of all pro- and eukaryotic relatives.

Several features make the Smc5/6 complex with its two SMC proteins (Smc5 and Smc6) and six 'Non-SMC Elements' (Nse1-6) profoundly different from cohesin and condensin (Haering and Gruber, 2016). The kleisin Nse4 is a comparatively small protein. It binds two interactors (Nse1 and Nse3) belonging to the KITE family rather than the HAWK family as in cohesin and condensin (Doyle et al., 2010; Palecek et al., 2006; Palecek and Gruber, 2015; Wells et al., 2017) ). The Nse2 subunit attaches to the coiled-coil arm of Smc5. It lacks known relatives in other SMC complexes (Duan $e t$ al., 2009a). Apart from the ATPase activity located in the Smc5 and Smc6 heads, the complex harbors a small ubiquitin-related modifier (SUMO) ligase activity in Nse2 (Andrews et al., 2005; Zhao and Blobel, 2005) as well as a ubiquitin ligase activity in Nse1 (Doyle et al., 2010). Mutants with disruptions in these enzymatic domains are viable but sensitive to DNA damage, and these activities are thus only required for non-essential functions of Smc5/6 (Andrews et al., 2005; Pebernard et al., 2008; Potts and Yu, 2005). Complete removal of any of these subunits is however lethal in yeast (McDonald et al., 2003).

The last two subunits, Nse5 and Nse6, form a stable heterodimer and have only very weak sequence similarity to their presumed vertebrate counterparts Slf1 and Slf2 (Raschle et al., 2015). Experiments on this sub-complex performed in budding and fission yeast have yielded several disparate results. While Nse5/6 has been reported to bind to the head-proximal region of the Smc5/6 hexamer in S. pombe (Palecek et al., 2006), it was shown to bind to the hinge domain in $S$. cerevisiae (Duan et al., 2009b). Recent mapping experiments with human Slf1/2 showed a binding mode similar to that observed in fission yeast (Adamus et al., 2020). While neither Nse5 nor Nse6 are essential in S. pombe they are required for viability in all other organisms tested (Aragon, 2018; Oravcova et al., 2019). Nse5/6 is involved in the DNA-repair function of Smc5/6 (Bustard et al., 2012; Pebernard et al., 2006), potentially by working together with Nse2 in substrate SUMOylation (Bustard et al., 2016)). It also has a role in recruiting the Smc5/6 complex to DNA damage sites through an interaction between an $\mathrm{N}$-terminal unstructured peptide in Nse6 and a multi-BRCT domain of Rtt107 (Leung et al., 2011; Wan et al., 2019). Single-molecule tracking recently suggested a function for Nse5/6 in chromosomal loading of Smc5/6 (Etheridge et al., 2020).

To elucidate the function of budding yeast Nse5/6 we determined the Nse $5 / 6$ crystal structure and investigated its interaction with the Smc5/6 core hexamer as well as its influence on the Smc5/6 ATPase. We found that Nse5/6 strongly inhibited Smc5/6 ATPase function by preventing productive ATP binding, likely by inducing a major rearrangement of the Smc5 and Smc6 head domains. Addition of plasmid DNA, but not of short linear molecules, robustly stimulated ATP hydrolysis by the holo-complex but not the core hexamer, thus suggesting that Nse5/6 modulates DNA substrate selection by the Smc5/6 ATPase. To elucidate the organization of the holo-complex, we performed cross-linking mass spectrometry experiments (XLMS). The data revealed major conformational changes involving the Nse4/3/1 kleisin/KITE module upon ATP and DNA binding. In summary, our experiments demonstrate that Nse5/6 is a key partner that associates with the Smc5/6 heads to modulate the ATP hydrolysis rate of Smc5/6 in response to DNA substrate binding.

\section{Results}

Reconstitution of the Smc5/6 octamer. Here, we focused on the biochemical and structural analysis of the 'loader' Nse5/6 in the context of the Smc5/6 holo-complex. To do so, we separately reconstituted the Smc5/6 core hexamer of yeast origin and the corresponding Nse5/6 dimer by co-expression of subunits in E. coli. The hexamer was enriched by affinity purification using a Twin-Strep-tag on Smc6, while the dimer was purified using a His-tag on Nse6 and a Twin-Strep-tag on Nse5. The protein preparations were further polished by ion exchange chromatography and gel filtration. Both complexes eluted from an analytical gel filtration column as a single species with apparently stoichiometric subunit composition (Fig 1A). Mixing of the hexamer and dimer prior to gel filtration resulted in a shift to a smaller elution volume, indicating the formation of a stable Smc5/6 octamer. Gel analysis confirmed that Nse5 and Nse6 proteins co-eluted with the subunits of the Smc5/6 hexamer (Fig S1a).

The architecture of Smc5/6. To determine the overall organization of the Smc5/6 octamer, we first performed lysine-specific XL-MS to identify residues in close proximity. Using the short-spacer, enrichable, lysine-reactive cross-linking reagent PhoX (Steigenberger et al., 2019), we detected 98 intra-subunit cross-links (intralinks) as well as 64 inter-subunit cross-links (interlinks) on the reconstituted Smc5/6 octamer in a buffer containing $250 \mathrm{mM} \mathrm{NaCl}$ (Fig 1B). Additional cross-links were detected with another buffer (see below). The pattern of intralinks was generally in good agreement with available structural information. A sizeable fraction of the interlinks were located between the coiled coils of Smc5 and Smc6, strongly supporting the notion of the co-alignment of the Smc5 and Smc6 coiled coils from the hinge to the head domains in a juxtaposed conformation (J-state) 
bioRxiv preprint doi: https://doi.org/10.1101/2021.02.09.430422; this version posted February 9, 2021. The copyright holder for this preprint (which was not certified by peer review) is the author/funder, who has granted bioRxiv a license to display the preprint in perpetuity. It is made available under aCC-BY 4.0 International license.
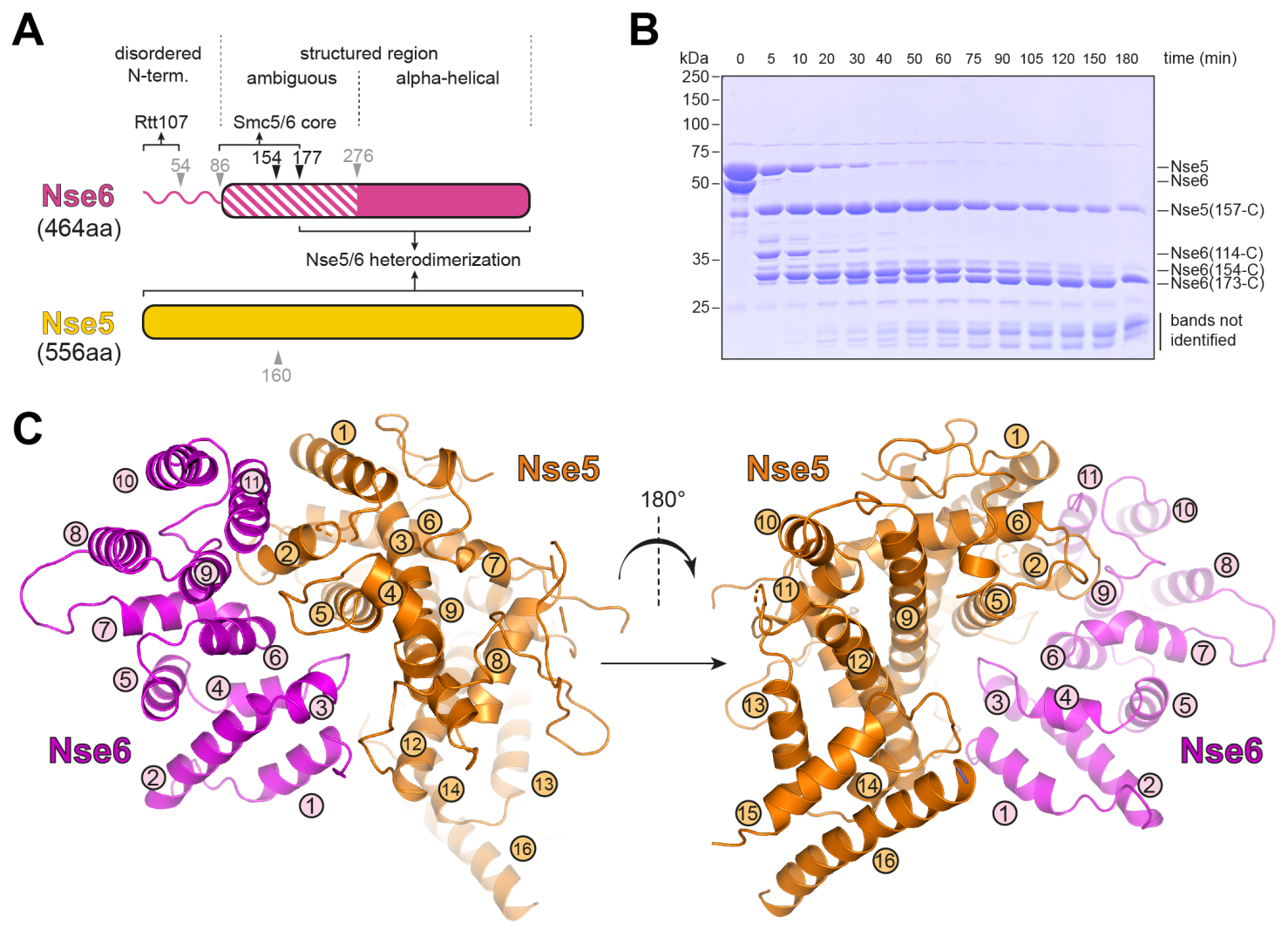

D
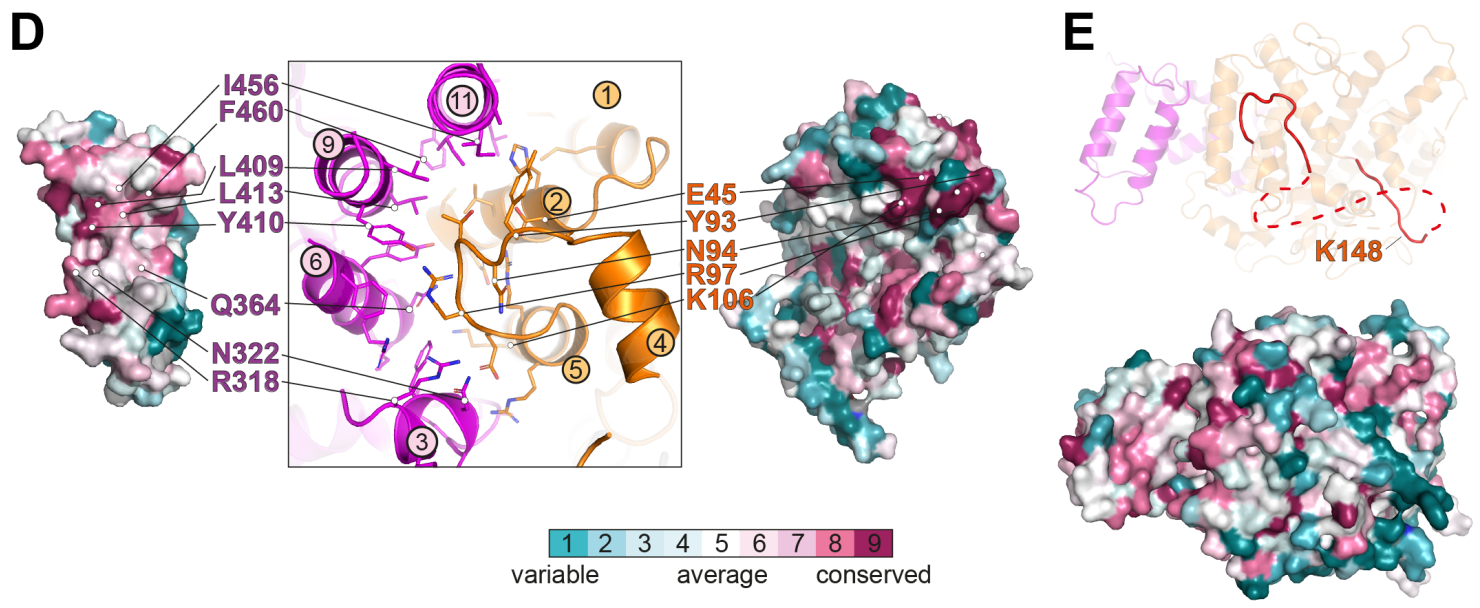

Figure 2. A Nse5/6 co-crystal structure. A. Domain organization of Nse5 and Nse6 proteins. Putative domain boundaries identified by secondary structure prediction and limited proteolysis are denoted by arrowheads, in black colours when producing stable fragments, otherwise in grey colours. B. Limited proteolysis of a purified preparation of the Nse5/Nse6 complex by trypsin. Samples taken at different time points were analyzed by SDS-Page and Coomassie staining. Selected stable fragments were identified by mass spectrometry. C. Front and back view of the Nse5/Nse6 co-crystal structure in cartoon representation. Structural elements of Nse5 and Nse6 are displayed in orange and purple colours, respectively. $\alpha$-helices are labelled. D. Conservation of residues at the Nse5/6 binding interface. Interaction surface of Nse6 (left panel) and Nse5 (right panel). For orientation, the secondary structure at the interface is displayed (middle panel). Colour code for residue conservation is given at the bottom of the panel. E. A conserved surface area (bottom panel) on top of Nse5/6. Colour coding for conserved residues as in (D).

(Fig 1C). Under these conditions, only one intra-subunit cross-link (in red colors) deviated from this Smc5/6 rod pattern, which could represent a false positive hit as the data analysis was cut off at $1 \%$ false positive rate. The cross-link may also have formed between two Smc5 proteins. Similar cross-linking was performed in a different buffer yielding largely comparable results that are discussed below.
The cross-links of Smc5 and Smc6 residues to the other subunits, including Nse5 and Nse6, are also discussed further below, in the context of the Nse5/6 crystal structure.

To investigate the putative folding of Smc5/6 arms by a complementary method, we analyzed yeast $\mathrm{Smc} 5 / 6$ hexamers by cryogenic electron microscopy. We obtained 2D class averages that showed 

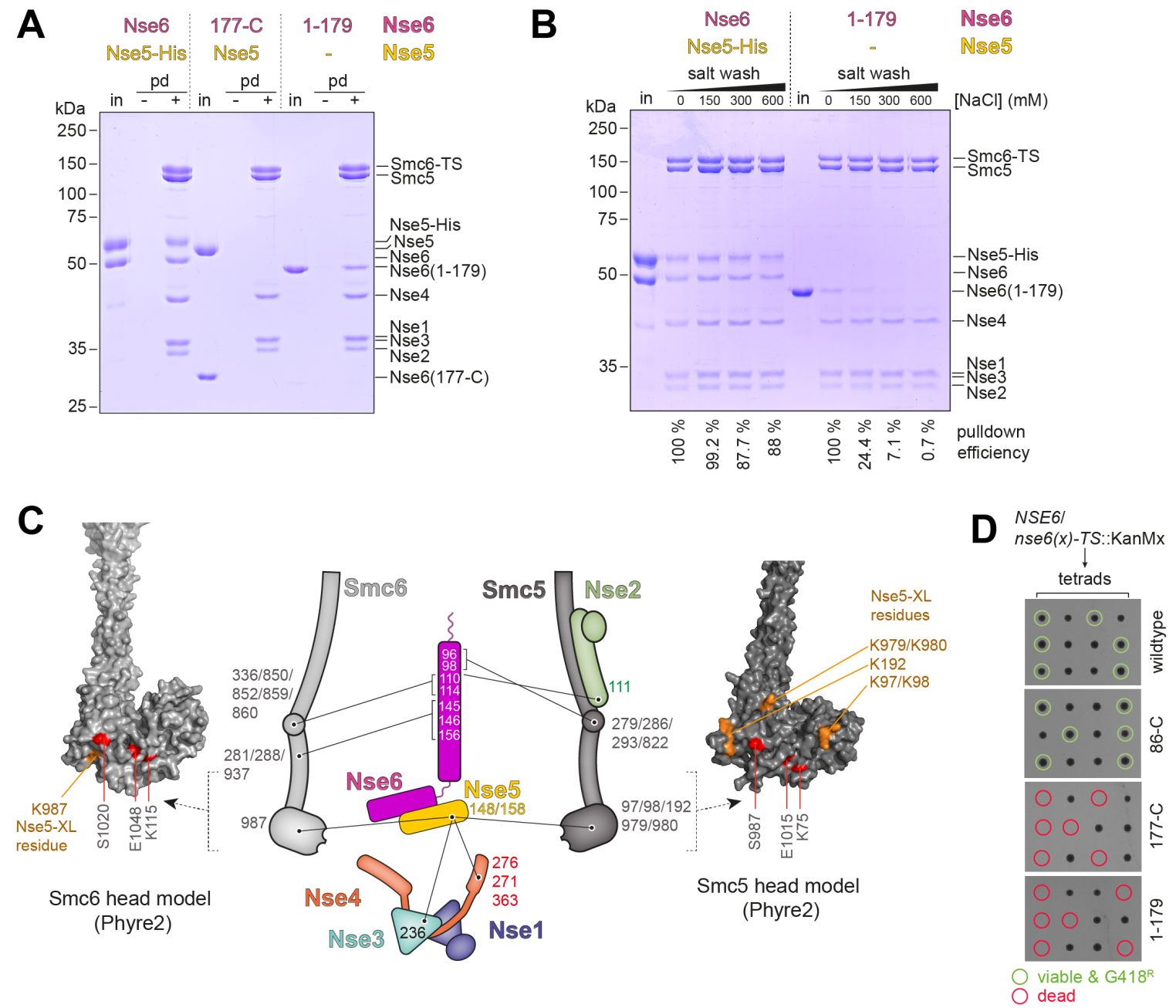

Figure 3. Association of the yeast Smc5/6 hexamer with the Nse5/6 dimer. A. Pulldown ('pd') assays using immobilized Smc5/Smc6-Twin-Strep ('TS') hexamers and soluble input material ('in') of Nse5/6 (left), of Nse5/Nse6(177-C) (middle) and of Nse6(1-179)-CPD (right). Control pulldowns ('-') were performed by omitting the pre-binding of Smc5/Smc6-Twin-Strep to the beads. B. Salt stability of Smc5/Smc6-Twin-Strep interactions with Nse5/6 and Nse6(1-179). Immobilized Smc5/Smc6-Twin-Strep was mixed with Nse5/6 or Nse6(1-179)-CPD ('in'). Beads were washed with buffers containing the indicated salt concentrations. C. Cross-links between Nse5 and Nse6 proteins and subunits of the Smc5/6 hexamer in schematic representation (middle panel). The positions of lysine residues on the Smc6 head and the Smc5 head, left and right panels, respectively, with cross-links to Nse5 are denoted on Phyre2-generated homology models. D. Analysis of spore viability by yeast tetrad dissection. Diploid strains heterozygous for alleles of Nse6 (wt, 86-C, 177-C and 179-C) were sporulated. Viable clones marked by circles in green colours. Dead spores were marked by circles in red colours.

highly elongated particles with a length of about $40 \mathrm{~nm}$, consistent with fully extended and co-aligned Smc5/6 arms (Fig 1D, images 1 and 2). An additional density along the arms was noticeable at the anticipated position for the Nse 2 subunit. Near the head domains, individual arms were recognizable, often in a slightly bent form as expected from a disruption in the coiled coil structure near the heads, called the SMC joint (Diebold-Durand et al., 2017). Of note, some class averages included dimeric forms of the hexamer in a head-tohead configuration (Fig 1D, images 3 and 4). The relevance of these dimers remains to be determined.

Crystal structure of Nse5/6. Structural information on the Nse5/6 complex is currently limited to the disordered N-terminus of Nse6 that interacts with Rtt107 (Wan et al., 2019). Compounding this, there are conflicting reports in the literature on the presence of $\alpha$ - helical HEAT repeats in Nse6 and its putative relatedness to human Slf2, a subunit of the Smc5/6 associated Slf1/Slf2 complex (Adamus et al., 2020; Pebernard et al., 2006; Raschle et al., 2015; Yu et al., 2021). Limited proteolysis of purified Nse5/6 (Fig 2B) led to the design of two N-terminally truncated Nse6 fragments (154-C and 177-C) which were easily co-purified with Nse5 indicating a stable interaction with Nse5. The Nse5/Nse6(177-C) complex yielded selenomethionine substituted protein crystals that diffracted to $3.3 \AA$ resolution and provided experimental phase information to compute an electron density of high enough quality to build a structural model (Fig 2C and S2) (Table 1). In the electron density map, residues 284-464 of Nse6 were visible, corresponding to the domain with predicted $\alpha$-helical secondary structure (Fig 2A). It indeed folds into $11 \alpha$-helices, arranged in an overall crescent-shaped structure (Fig $2 \mathrm{C}$, and S2A). We did not observe reliable density for Nse6 residues 

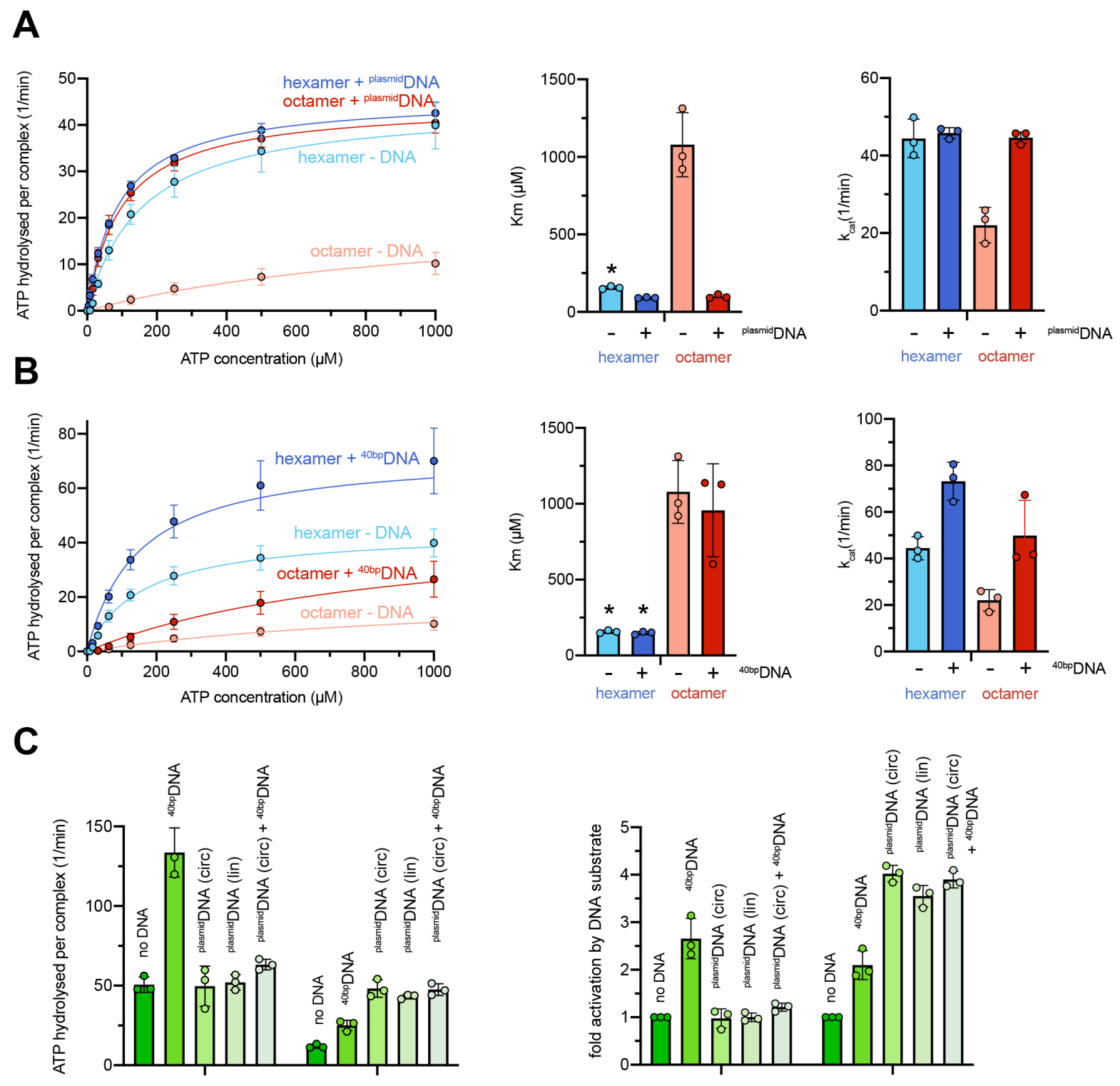

hexamer

octamer

hexamer

octamer

Figure 4. ATP hydrolysis by purified Smc5/6 hexamer and octamer. A. ATP hydrolysis rates (per Smc5/6 complex) were measured by an enzymecoupled assay in the absence and presence of plasmid DNA (conc. $1.25 \mathrm{nM}$ ) for the Smc5/6 hexamer (conc. $150 \mathrm{nM}$ ) and the octamer (conc. $150 \mathrm{nM}$ ) with increasing concentrations of ATP. The curves were fitted to Michaelis Menten equation and Km and kcat values were determined. Please note that the

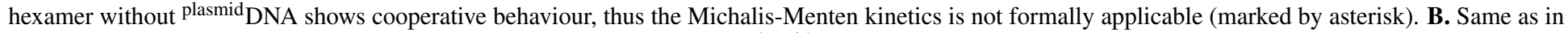
(a) using 40bpDNA (annealed 40 bp oligo DNA) (conc. $1 \mu \mathrm{M}$ ) instead of plasmid DNA. Note that the data points and curves for samples without DNA (hexamer-DNA; octamer-DNA) are identical to (A). C. Overview of values for ATP hydrolysis rates measured at an elevated ATP concentration (1 mM) (left panel) and fold-stimulation of ATP hydrolysis rates by addition of $40 \mathrm{bpDNA}$ (conc. $1 \mu \mathrm{M}$ ) or ${ }^{\text {plasmid }}$ DNA (conc. $1.5 \mathrm{nM}$ ) in closed covalent circular ('circ') or linearized form ('lin') (right panel).

177-283, indicating flexibility in this region in the crystal. For Nse5, we observed clear density for $16 \alpha$-helices formed by residues 2-518 (Fig 2C and S2B), with some of the helices being connected by apparently extended loops (147-197, 290-340 and 430-491), for which we only detected poor density or none at all.

The Nse5/6 interaction interface covers around $1300 \AA^{2}$ in the crystal (Fig 2D), as calculated by the PISA server (Krissinel and Henrick, 2007). On Nse6, it mainly involves residues located in helices $\alpha 3, \alpha 6, \alpha 9$, and $\alpha 11$ together forming a concave interaction surface with clear pattern of sequence conservation (Fig S2a). Its pronounced hydrophobic area packs tightly against Nse 5 residues forming helices $\alpha 2$ and $\alpha 5$, as well as a loop connecting helices $\alpha 4$ and $\alpha 5$. Sidechains around this hydrophobic pocket engage in further polar contacts. Additional, albeit less extended and conserved, contacts exist between residues in helix $\alpha 12$ as well as the preceding loop in Nse 5 with helices $\alpha 1$ and $\alpha 3$ of Nse6 (Fig. S2C). The unmodelled Nse6 sequences further towards the N-terminus might strengthen this part of the interface. Due to the large interaction surface and the fact 
that neither Nse6 nor Nse5 could be produced in isolation, we did not attempt to disrupt this interface by mutagenesis. Such mutations, however, have recently been reported based on a presumably related structure obtained by cryo-EM recently (Yu et al., 2021).

An extended surface area jointly formed by Nse5 and Nse6 residues displayed clear evolutionary conservation (Fig 2E). This surface is unlikely to bind to unmodelled N-terminal Nse6 residues as these regions would be located on the opposite side of the structure. This surface might be responsible for a putative interaction between Nse5/6 and the Smc5/6 core hexamer (see below).

We next searched for structural homologs using the DALI server (Holm, 2020). Searches with the complete Nse6(284-454) model in the Protein Data Bank revealed weak overall similarity (root mean square displacement (RMSD) i4 $\AA$ ) to a number of proteins, some of which contained HEAT repeats, with the best structural overlap found for the $4 \mathrm{C}$-terminal $\alpha$-helices. Searches for matches for only these $4 \mathrm{C}$-terminal helices, improved the RMSD values to a range of 2.0-2.6 $\AA$ for the best hits including eIF4G, Exportin-1, and PTAR1, all containing HEAT repeats (Dong et al., 2009; Kuchay et al., 2019; Marcotrigiano et al., 2001). Structural similarity was clearly visible upon manual superpositioning the corresponding regions (Fig S2D, left). Similar DALI searches for the Nse5 model did not reveal significant hits, suggesting that the overall fold was not observed in other proteins so far. Restricting the search for matches to only the isolated N-terminal region involved in the main interaction with Nse6 (Fig 2D), uncovered several hits with rather low RMSD values in the range of 2.9-4 $\AA$. Several of these again contained HEAT repeats, and a conserved overall positioning of individual helices was observed (Fig S2D, right).

The HEAT repeat-like organization in Nse5 and Nse6 is limited to the immediate interface. The Nse5/6 structure therefore does not display the characteristic hook-shaped architecture of many HEAT repeat proteins, including the HAWK subunits of cohesin and condensin. It thus remains unclear whether Nse5 and Nse6 have a common origin with these cohesin and condensin subunits. We speculate, however, that Nse5 and Nse6 have evolved from larger ancestral proteins being reminiscent of Slf1 and Slf2 by the loss of HEAT repeats.

Mapping of Nse $5 / 6$ contact points on the Smc5/6 hexamer. Next, we mapped the binding sites on the Nse5/6 dimer connecting to the Smc5/6 hexamer, by performing pulldown assays using truncated Nse5/6 constructs. The crystallized complex containing the truncated Nse6 fragment (177-C) bound to Nse5 failed to stably associate with the Smc5/6 hexamer in these assays (Fig 3A). An N-terminal Nse6 fragment (1-179) fused to a CPD-tag was also readily purified. It bound well to immobilized Smc5/6 hexamer (Fig 1D) but failed to co-purify with Nse5. The N- and C-terminal sequences of Nse6 are therefore sufficient for binding to the Smc5/6 hexamer and to Nse5, respectively. Moreover, we found that the binding of the Smc5/6 hexamer to Nse6(1-179) was salt labile, while the binding to fulllength Nse5/6 was resistant to washes up to $600 \mathrm{mM} \mathrm{NaCl}$. This indicates that additional sequences contribute to the formation of a stable octameric complex (Fig 3B). Supporting this notion, we found that Nse5/6 outcompeted the N-terminal fragment of Nse6 in binding to the Smc5/6 hexamer (Fig S3A) and was itself not dissociated from the hexamer by repeated washes with an excess of this Nse6 fragment (Fig S3B). For Nse5, an N-terminal fragment (1-160) and the corresponding C-terminal fragment (160-C) turned out to be poorly expressed even when Nse6 was co-expressed, presumably due to the folding of Nse5 into a single globular domain as seen in the crystal structure (Fig 2C), thus preventing the mapping of binding sites by truncations.

In our XL-MS data, we detected multiple inter-domain crosslinks between Nse5/6 and the Smc5/6 hexamer (Fig 3C), which are in line with the putative interface determined by pulldown assays and also with independent XL-MS experiments published while this work was in progress (Gutierrez-Escribano et al., 2020; Yu et al., 2021). Curiously, no cross-links were observed between Nse5 and Nse6 despite the clear presence of lysine residues in favorable positions in our crystal structure. N-terminal sequences of Nse6 displayed several contact points with the hexamer, consistent with the binding of Nse6(1-179) to Smc5/6 (Fig 3A) observed in our pulldown assays. The observed inter-domain cross-links clustered on the Smc5 and the Smc6 joint regions as well as the joint-proximal part of the Nse2 protein. On the other hand, Nse5 residues cross-linked to the head domains of Smc5 and Smc6 as well as to the Nse1/3/4 sub-complex, suggesting that the Nse5/6 dimer bridges distal parts of the Smc5/6 hexamer by contacting the joint region via Nse6 sequences and the head region via Nse5 sequences. Intriguingly, several Nse5 interdomain cross-links to Smc5/6 mapped to the direct vicinity of the Walker A and B box and signature motif residues. This suggests that Nse $5 / 6$ is located between the Smc5 and Smc6 heads, and if so, interferes with the ATP hydrolysis cycle (see below). On the Nse5/6 structure, the two Nse5 lysine residues that form cross-links to the Smc5 and Smc6 head domains are located in a loop between helices $\alpha() 6$ and $\alpha() 7$. K148 is visible, while reliable electron density was not observed for K158 in our crystal. Interestingly, this loop protrudes from the structure next to a highly conserved surface patch (Fig 2E), supporting the hypothesis that this region is involved in interaction between Smc5/6 and Nse5/6 complexes.

To establish whether the Nse6 sequences mediating binding to Nse 5 and Smc5/6 are required for cellular function, we next generated truncation mutants of the nse 6 gene in yeast by allelic replacement in a diploid strain. Isolation of haploid progenies by germination of spores showed that the Nse6(86-C) fragment was able to support apparently normal growth (Fig 3D), while Nse6(1-179) and (177-C) failed to do so. Combined, the observations support that both the $\mathrm{N}$ terminal Smc5/6 interacting region and the Nse5-binding C-terminus are crucial for correct function of Nse $5 / 6$ in yeast, while the extreme $\mathrm{N}$-terminal sequences (1-84) known to bind to the DNA repair factor Rtt107 are dispensable (Wan et al., 2019).

Nse5/6 inhibits the Smc5/6 ATPase. We next characterized the ATP hydrolysis activity of purified preparations of Smc5/6 complexes. Under our experimental conditions (150 $\mathrm{nM}$ protein in ATPase buffer), the hexamer exhibited an ATP hydrolysis rate of approximately $40 \mathrm{ATP} / \mathrm{min} /$ complex in the absence of DNA, which is in the typical range for SMC complexes (Fig 4A). This basal activity was virtually unchanged by addition of plasmid DNA ( 'plasmid DNA'; $25 \mathrm{kbp} ; 250 \mathrm{bp}$ DNA per hexamer) in closed circular form or after linearization (Fig 4A, 4C). As expected, an equivalent preparation 
bioRxiv preprint doi: https://doi.org/10.1101/2021.02.09.430422; this version posted February 9, 2021. The copyright holder for this preprint (which was not certified by peer review) is the author/funder, who has granted bioRxiv a license to display the preprint in perpetuity. It is made available under aCC-BY 4.0 International license.
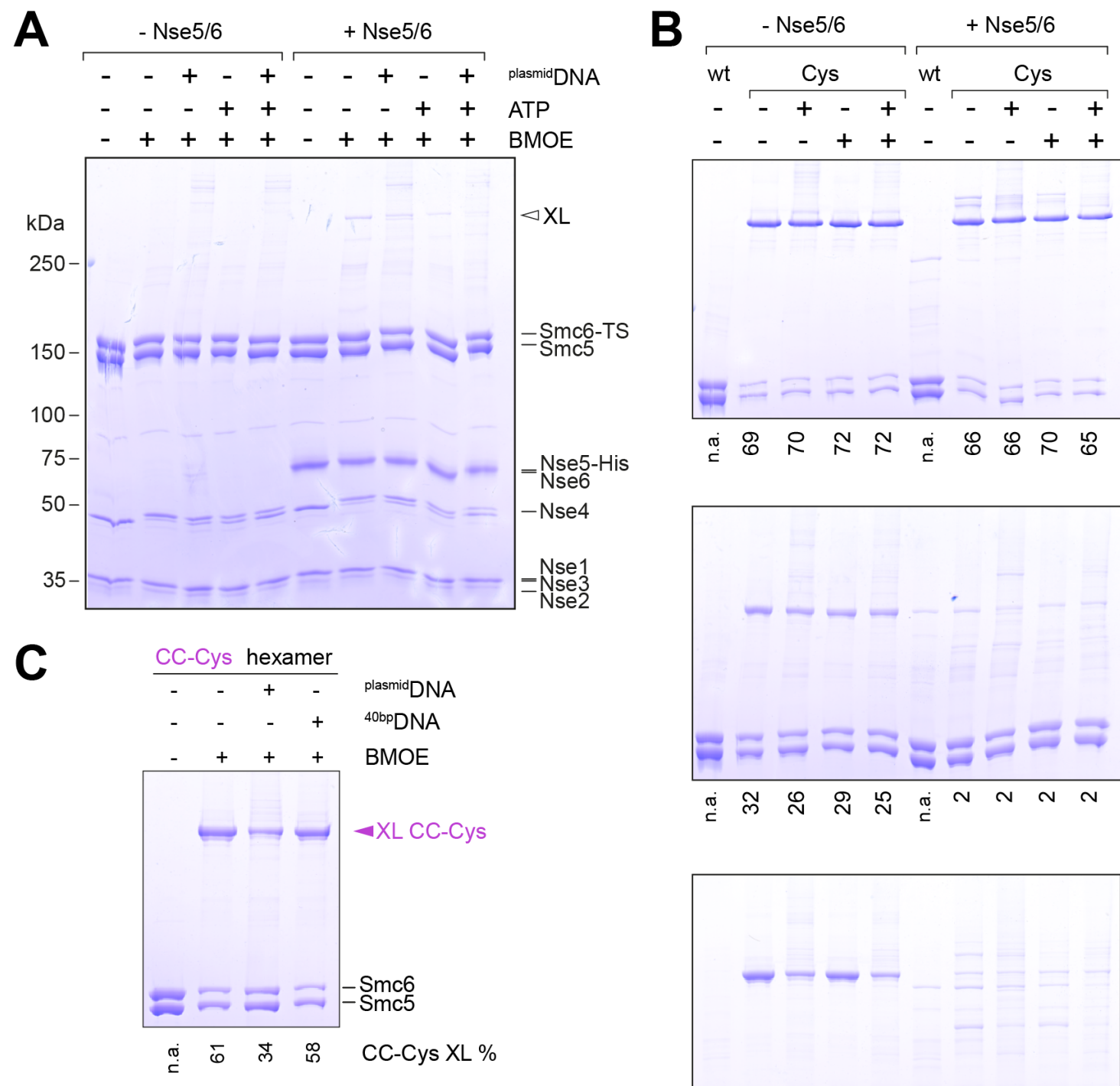

Smc5/6
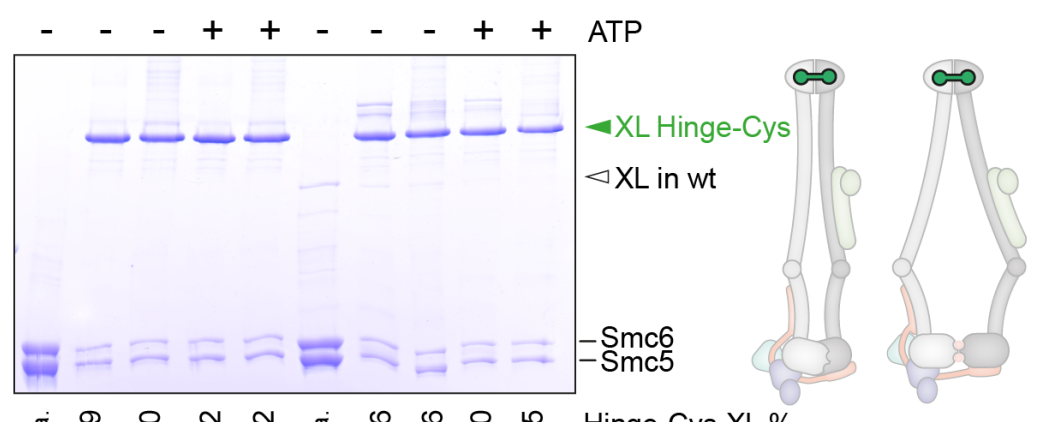

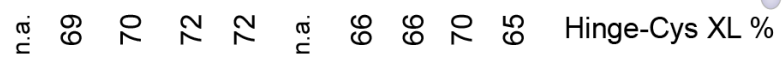
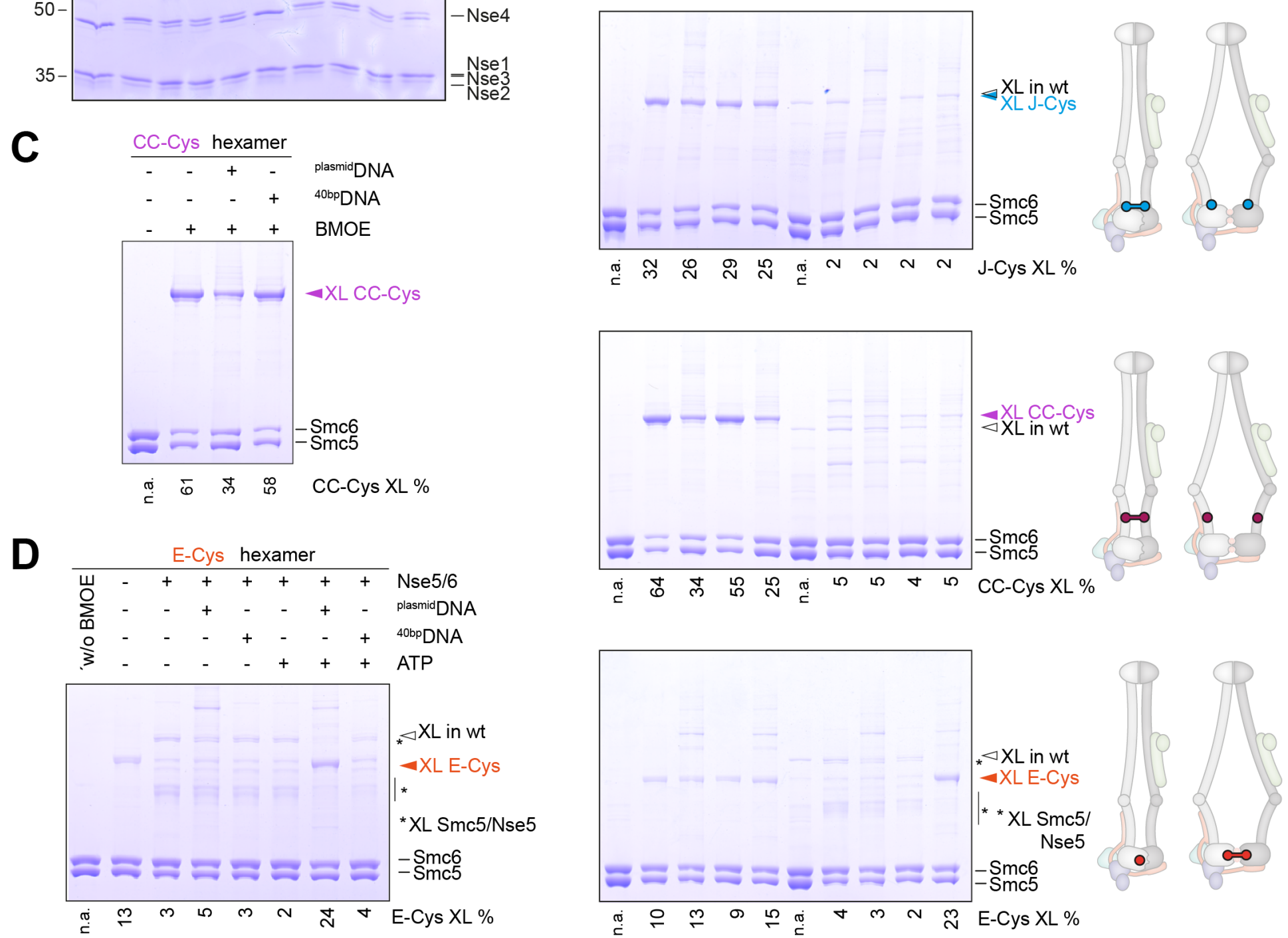

Figure 5. Detection of Smc5/6 conformations by cysteine cross-linking. A. Cross-linking of a purified preparation of wild-type Smc5/6 hexamer in the

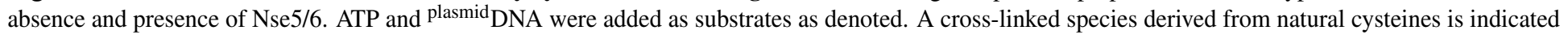
by an arrowhead ('XL'). B. Cross-linking of engineered variants of the Smc5/6 hexamer. As in (a) using Smc5 and Smc6 cysteine mutants. Schemes indicate the location of engineered cysteines and their expected ability to cross-link in a rod-like and a ring-like conformation. Wild-type hexamer ('wt') is included as cross-linking control. Species occurring only in the presence of engineered cysteines are labelled by coloured arrowheads. C. DNA effects on Smc5/6 arm co-alignment as judged by CC-Cys cross-linking. As in (b) but also including 40bpDNA. Addition of plasmid DNA but not 40bpDNA reduces CC-Cys cross-linking in the Smc5/6 hexamer. D. DNA effects on ATP-engagement as judged by E-Cys cross-linking. As in (b) also including 40bpDNA. 
harboring a Walker B motif active site mutation ('EQ') in Smc5 and in Smc6 did not display noticeable ATP hydrolysis activity, confirming the absence of contaminating activities and underscoring the importance of the Walker B motif in Smc5 and Smc6 for ATP hydrolysis (Fig S4A).

Addition of Nse5/6 strongly inhibited the Smc5/6 ATPase (Fig 4A). This inhibition was particularly strong at lower ATP concentrations and can thus largely be attributed to a reduction in the apparent affinity for ATP (i.e. an increased Km for ATP binding). At saturating ATP concentrations, the decrease in turnover (kcat) was comparatively mild (approximately two-fold). This implies that Nse5/6 mainly inhibited the ATPase activity by precluding productive ATP binding by Smc5/6. It might do so by either interfering directly with the ATP binding step or by preventing subsequent head engagement, which completes the formation of the ATP binding pocket. Both scenarios are consistent with the proximity of Nse5 residues to the active site of Smc5 and Smc6 as detected by XL-MS (Fig 3C). Of note, to our knowledge this is the first documented example of a SMC associated protein acting as a strong ATPase inhibitor.

Unlike the hexamer, the Smc5/6 octamer showed robust stimulation of ATP hydrolysis by addition of plasmid DNA, yielding an ATP hydrolysis rate of approximately 40/min/complex (Fig 4A). The presence of ${ }^{\text {plasmid }}$ DNA lowered the Km for ATP and increased the kcat, essentially cancelling the inhibitory effects of Nse5/6 on the hexamer (Fig 4A). The addition of equivalent concentrations (1 $\mu \mathrm{M}$; i.e. $250 \mathrm{bp}$ DNA per octamer) of $40 \mathrm{bp}$ double stranded DNA ('40bpDNA') had little to no effect on Km (Fig 4B).Together these observations indicating that only larger DNA molecules alleviate the inhibition of the Smc5/6 ATPase by Nse5/6, which suggests that a given DNA molecule might have to occupy multiple DNA binding sites simultaneously to efficiently stimulate ATP hydrolysis in the octamer. We hypothesize that DNA competes with Nse5/6 for binding to the Smc5/6 head domains thus counteracting Nse5/6 to allow for productive head engagement.

While ${ }^{\text {plasmid }}$ DNA stimulated the octamer more strongly when compared to 40bpDNA, the hexamer curiously showed the opposite response. Its kcat was mildly but clearly stimulated (roughly twofold) by the addition of 40bpDNA (Fig 4B, 4C). Intriguingly, the presence of ${ }^{\text {plasmid }}$ DNA hindered the stimulation of the hexamer by 40bpDNA (Fig 4C), suggesting that both types of DNA molecule compete for same DNA binding interface, although only the less stably bound 40bpDNA leads to ATPase stimulation. The Smc5/6 hexamer furthermore exhibited cooperativity i.e. the ATP hydrolysis rate per Smc5/6 complex increased with elevated protein concentrations (Fig S4). This implies that at least some of the observed ATP hydrolysis occurred in a dimer of hexamers or a higher oligomeric form, unlike for instance the ATP hydrolysis activity of B. subtilis Smc-ScpAB (Vazquez Nunez et al., 2019). The octamer did not show cooperativity in the measured range of concentrations (Fig S4), implying that Nse5/6 excluded productive association between Smc5/6 complexes.

Nse5/6 couples head engagement to DNA substrate selection. To test if Nse5/6 modulates the Smc5/6 ATPase by hindering head engagement, we made use of site-directed chemical cross-linking with the thiol-specific short-spacer compound BMOE. All eight subunits of the Smc5/6 holo-complex naturally harbor cysteine residues (64 in total). Chemical cross-linking of these residues produced subtle effects observed by SDS-Page (Fig 5A). Presumably due to internal cross-linking or mono-link modifications (i.e. one reactive group of the reagent reacted with a cysteine while the other group quenched), some of Nse4 migrated slightly slower through the gel (Fig 5A). At a low abundance, other cross-linked products appeared, particularly in the presence of ${ }^{\text {plasmid }}$ DNA, which likely leads to increased local concentration, and upon addition of Nse5 and Nse6. Otherwise, the electrophoretic mobility of proteins remained virtually unchanged indicating that the cross-linking of engineered cysteines might be readily detectable (Davidson et al., 2019).

As a proof-of-principle, we first engineered a pair of cysteine residues at the interface between Smc5 and Smc6 hinge domains ('Hinge-Cys') based on structural information available for the fission yeast hinge (cit. Alt et al; Fig S5A) (PDB: 5MG8). BMOE treatment of purified Hinge-Cys preparations depleted Smc5 and Smc6 and generated a species that migrated slowly in SDS-Page, corresponding to the molecular weight of the cross-linked Smc5-Smc6 product (Fig 5B). Hinge-Cys cross-linking was robust and unaffected by addition of ATP, plasmid DNA, or Nse5/6. Next, we designed a pair of cysteines to detect the juxtapositioned Smc5/6 heads ('J-Cys') based on models of the rod-shaped conformation of the prokaryotic Smc-ScpAB complex (Diebold-Durand et al.) (Fig S5B and S5C). J-Cys cross-linking was clearly detected in the hexamer (Fig. 5B). The cross-linking efficiency was not markedly altered by the

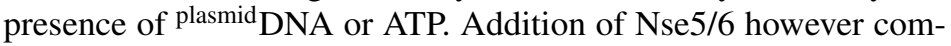
pletely abolished J-Cys cross-linking regardless of the presence or

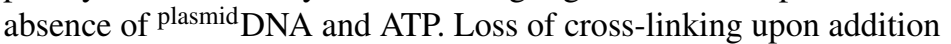
of Nse $5 / 6$ was also observed with a pair of cysteines located in the head-proximal coiled coils (Fig. 5B and S5C). These cysteines ('CCCys') were again designed based on published information for the prokaryotic Smc-ScpAB complex with the aim to detect co-aligned Smc5/6 arms. The cross-linking efficiency with CC-Cys was also significantly lowered (but not abolished) by the addition of ${ }^{\text {plasmid }}$ DNA (Fig 5B) but not 40bpDNA (Fig 5C) or ATP. These results confirmed our hypothesis that Nse5/6 alters the organization of Smc5/6 heads as well as the head-proximal coiled coils. Binding of Nse5/6 appears to destabilize the rod conformation (J-state) as judged by J-Cys and CC-Cys cross-linking.

As Nse5/6 interferes with ATP hydrolysis of Smc5/6, we next engineered cysteines for the detection of head engagement by BMOE cross-linking. The first attempted design based on an equivalent reporter in bacterial Smc-ScpAB failed due to instability of the mutant proteins (Minnen et al. 2016). Thus, we utilized naturally occurring cysteines on the Smc6 head (C92 and C147) and introduced a complementary cysteine residue on Smc5 (N975C), so that a pair of cysteines ('E-Cys') would get cross-linked upon ATP-engagement (Fig. S5C). E-Cys cross-linking was detected at low levels in the hex-

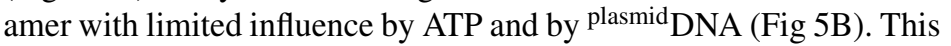
suggest that the Smc5 and Smc6 heads are arranged in a relatively flexible manner in the hexamer and are able to adopt both the J-state as well as the E-state. Like J-Cys and CC-Cys cross-linking, also E-Cys cross-linking was strongly reduced by the addition of Nse $5 / 6$ (Fig 5B). Of note, minor levels of other cross-linked species appeared 
that were putatively derived from off-target cross-linking between residue N975C in Smc5 and an endogenous cysteine on Nse5 or Nse6. More importantly and unlike J-Cys and CC-Cys cross-linking, E-Cys cross-linking was boosted when ATP and plasmid DNA were supplemented in the presence of Nse5/6 (Fig 5B). This suggests that Nse5/6 hinders head engagement in the absence of a suitable DNA substrate and promotes engagement in its presence. 40bpDNA was not able to substitute for ${ }^{\text {plasmid }}$ DNA in overcoming the inhibition by Nse5/6 (Fig 5D) as expected from its failure to stimulate ATP hydrolysis by the octamer efficiently (Fig 4B).

We conclude from these results that binding of Nse5/6 to the Smc5/6 hexamer reorganizes the Smc5/6 head module in a manner that reduces the occupancy of the J-state and of the E-state by stabilizing yet another conformation,. As Nse5/6 may keep Smc5 and Smc6 heads apart by intercalating between them, possibly analogous to the apo-bridged conformation of the Smc2 and Smc4 heads observed with yeast condensin (Lee et al., 2020), we tentatively call this conformation the 'inhibited' conformation (with the heads occupying the 'I-state')). Only in the presence of ATP and ${ }^{\text {plasmid DNA, the }}$ inhibitory effect of Nse $5 / 6$ is overcome making head engagement a favorable conformation.

\section{Global changes in Smc5/6 architecture upon ATP and plasmid DNA}

binding. To detect the conformational changes in an unbiased manner, we next performed XL-MS on Smc5/6 octamers in the absence

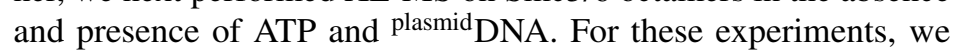
switched to using the ATPase buffer (10 mM Hepes- $\mathrm{KOH} \mathrm{pH} 7.5$; $150 \mathrm{mM} \mathrm{K}-\mathrm{OAc} ; 2 \mathrm{mM} \mathrm{MgCl} 2,20 \%$ glycerol) so that the conditions matched those used for the ATP hydrolysis measurements. In general, we observed more cross-links (207 intralinks and 169 interlinks) under these conditions than with the buffer used for our initial XL-MS experiments (20 mM Hepes-KOH pH 7.5; $250 \mathrm{mM}$ $\mathrm{NaCl}$ ). The cross-links in the absence of substrate were however were largely comparable with the previously obtained XL-MS data (Fig 1B). Some additional cross-links were detected that appeared to deviate from the Smc5/6 rod pattern, many of which exhibited however relatively low MS cross-link identification scores (Fig 6A). Moreover, their positions were difficult to reconcile with one another and with the position of an elbow inferred from predicted discontinuities in the heptad register (Burmann et al., 2019). We thus presume that these cross-links were (at least largely) derived from spurious contacts between hexamers, which might be favorable in the ATPase buffer, or arise from the pool of 1

The total number of intralinks as well as the identity of most cross-links were also comparable in the presence and absence of the substrates. Smc5/6 inter- and intra-domain cross-links were not obviously changed, implying that any substrate-induced structural changes during the ATP hydrolysis cycle (such as head-engagement and putative arm opening) were not captured by the lysine-specific cross-linking reagents (Fig 6A). Nse2 forms inter-domain cross-links to both Smc5 and Smc6, which were also virtually unchanged by addition of the ligands (Fig. S6A). However, we observed striking differences in the pattern for other modules. Most importantly, a majority of Smc5 and Smc6 inter-domain cross-links to Nse3 and to

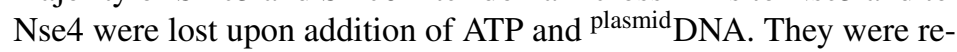
placed by a low number of new contacts (Fig 6B). Inter-domain cross- links between Nse3 and Nse4 were also dramatically reduced under these conditions. Similar and even more pronounced differences were observed for interactions between the Nse1/3/4 and Nse5/6 modules, which were well connected in the absence of ligands but not in their presence (Fig 6C). Whereas some differences were also observed for cross-links between Nse5/6 and the Smc5 and Smc6 proteins, they were much less severe and the interaction between the Nse6 Nterminus and the Smc5/6 joint region appeared unaffected (Fig. S6B). These results suggest that the Nse1/3/4 module is re-arranged and released from both the Nse5/6 module as well as the Smc5/6 heads in response to head engagement and ${ }^{\text {plasmid }}$ DNA binding. Very similar results were obtained when both Smc5 and Smc6 heads carried the 'EQ' mutation, demonstrating that ATP hydrolysis is not required for these global structural changes (Fig S6C).

\section{Discussion}

In this work, we investigated the architecture of Smc5/6 to elucidate the structural features it shares with other SMC complexes and features those that are exclusive to this family of proteins, with the aim to advance our understanding of Smc5/6's specialized functions and mechanisms. By separately reconstituting a hexameric Smc5/6 corecomplex and a dimeric Nse5/6 loader complex, we have uncovered the strong impact Nse5/6 plays on the organization of the Smc5/6 complex and on the regulation of the essential enzymatic activity of the complex-ATP hydrolysis-by mutations, pulldowns, cysteine cross-linking and state-of-the-art cross-linking mass spectrometry experiments.

Our data shows that Nse $5 / 6$ has multiple contact points with the Smc5/6 complex. The main anchor appears to be formed by physical association of the N-terminus of Nse6 with the Smc5/6 dimer as shown by pulldowns (Fig. 3A, 3B) and supported by recently published and our new XL-MS data (Fig. 3C and 6B) (GutierrezEscribano et al., 2020; Yu et al., 2021). The latter imply an interaction of the Nse6 N-terminus with the Smc5/6 joints, which is consistent with a domain mapping study using fission yeast proteins (Pebernard et al., 2006) but appears to contradict a mapping study based on budding yeast proteins which suggested that Nse5/6 may associate with the Smc5/6 hinge (Duan et al., 2009b). Binding assays under high salt conditions and with competition furthermore indicated that additional Nse 5 or Nse6 sequences strengthen the association in the octameric complex (Fig 3B and S3). In our XL-MS experiments, such contact points were indeed mapped, for example near the active sites of Smc5 and Smc6 and at a Nse5 surface located opposite of the Nse6 N-terminus (Fig 3C) (Gutierrez-Escribano et al., 2020). An equivalent interaction has recently also been mapped between the joint regions of human Smc5/6 and the loader Slf1/2 by Yeast-TwoHybrid assays (Adamus et al., 2020). Whether the yeast and human interfaces indeed share a similar fold and a common origin remains to be determined due to the absence of recognizable sequence conservation in the relevant regions. The positions of XL-MS inter-subunit cross-links suggested that Nse5/6 might modulate the ATP hydrolysis activity of Smc5/6. Consistent with this notion, we found that Nse5/6 strongly inhibited the basal activity of Smc5/6, either by directly blocking binding of ATP through interactions with active sites on Smc5 and Smc6 or by sterically blocking ATP-engagement of the 

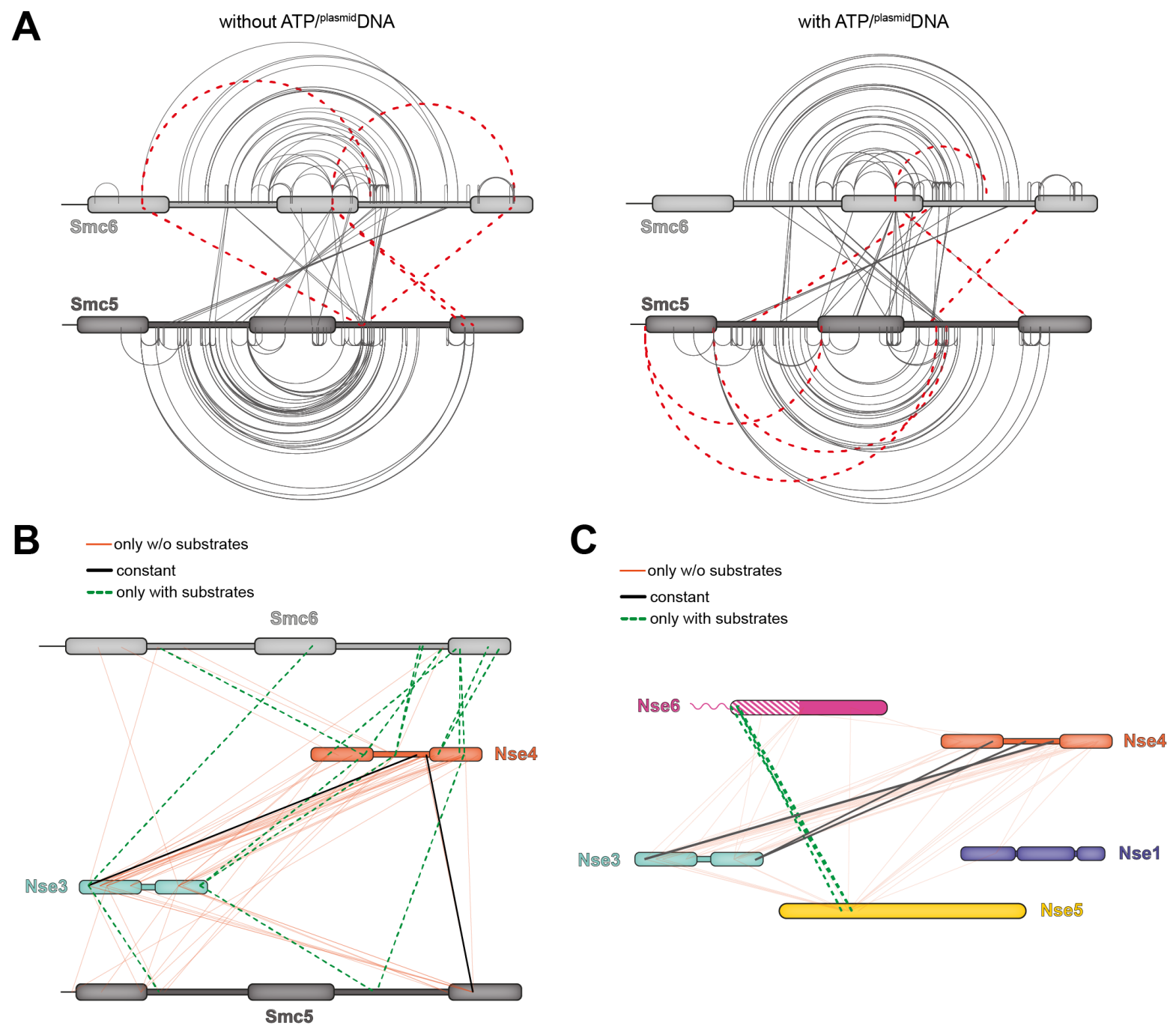

Figure 6. Figure 6: Alterations in the Smc5/6 architecture upon binding of ATP and plasmidDNA. A. Crosslinks in the Smc5/6 octamer identified by

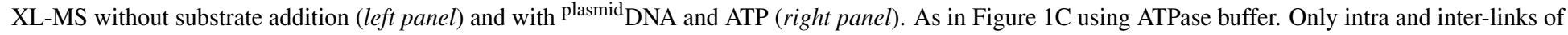
the Smc5/6 dimer are displayed here. Other cross-links are shown in panel (B), (C), and Fig S6. B. Crosslinks of Nse3/4 detected by XL-MS. Same experiment as in (A) using the Smc5/6 octamer in ATPase buffer. Cross-links between Nse3 and Nse4 as well as their cross-links to Smc5 and Smc6 are displayed. Lines in black colours indicate cross-links observed with and without substrates, in oranges colours only without substrates and in dashed lines in green colours only with substrate addition. C. Cross-links of Nse1/3/4 to Nse5/6. Same experiment as in (A) and (B). Display as in (B).

heads. Both scenarios would hinder productive ATP binding as deduced by the poor ATP hydrolysis at reduced concentrations of ATP (Fig 4A). Intriguingly, the SUMO-ligase activity of the Nse2 subunit has been reported to be controlled by DNA binding in an isolated Smc5/Nse2 sub-complex (Varejao et al., 2018) with the Smc5 arms reorganizing upon DNA binding, concomitant with Nse2 stimulation (Varejao et al., 2018). Moreover, Nse5 directly interacts with the substrate of the enzyme, the SUMO protein, via SIM sequences and might thus also promote SUMOylation of target proteins (Bustard $e t$ al., 2016; Yu et al., 2021). To reconcile these observations, we propose that the Nse5/6 complex, while being fastened onto the Smc5/6 joints by the Nse6 $\mathrm{N}$-terminus, can reach out - putatively via a flexible connection in Nse6 - to either inhibit the Smc5/6 ATPase located on one side of the Smc5/6 joints or to stimulate the Nse2 SUMO-ligase located on the opposite side by binding to the substrate SUMO (Fig
7). DNA binding would consequently activate not only the Smc5/6 ATPase by releasing the Nse $5 / 6$ inhibition but also stimulate target SUMOylation by Nse2. If so, then Nse5/6 would be a key regulator of at least two (of the three known) enzymatic activities in Smc5/6.

We provide several lines of evidence suggesting that the inhibition of the Smc5/6 ATPase is brought about by major conformational changes. As judged by cysteine cross-linking data, association of Smc5/6 with Nse5/6 eliminated the J-state regardless of substrate availability. It also abolished the E-state but only in the absence of

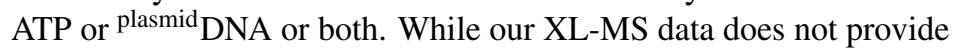
detailed information on this conformation, we propose that this inhibited conformation (the I-state) might resemble the apo-bridged conformation of condensin where a hawk subunit (Ycs4) distantly bridges the Smc2 and Smc4 heads (Lee et al., 2020). Since the Nse5/6 structure revealed rudimentary structural similarities with 


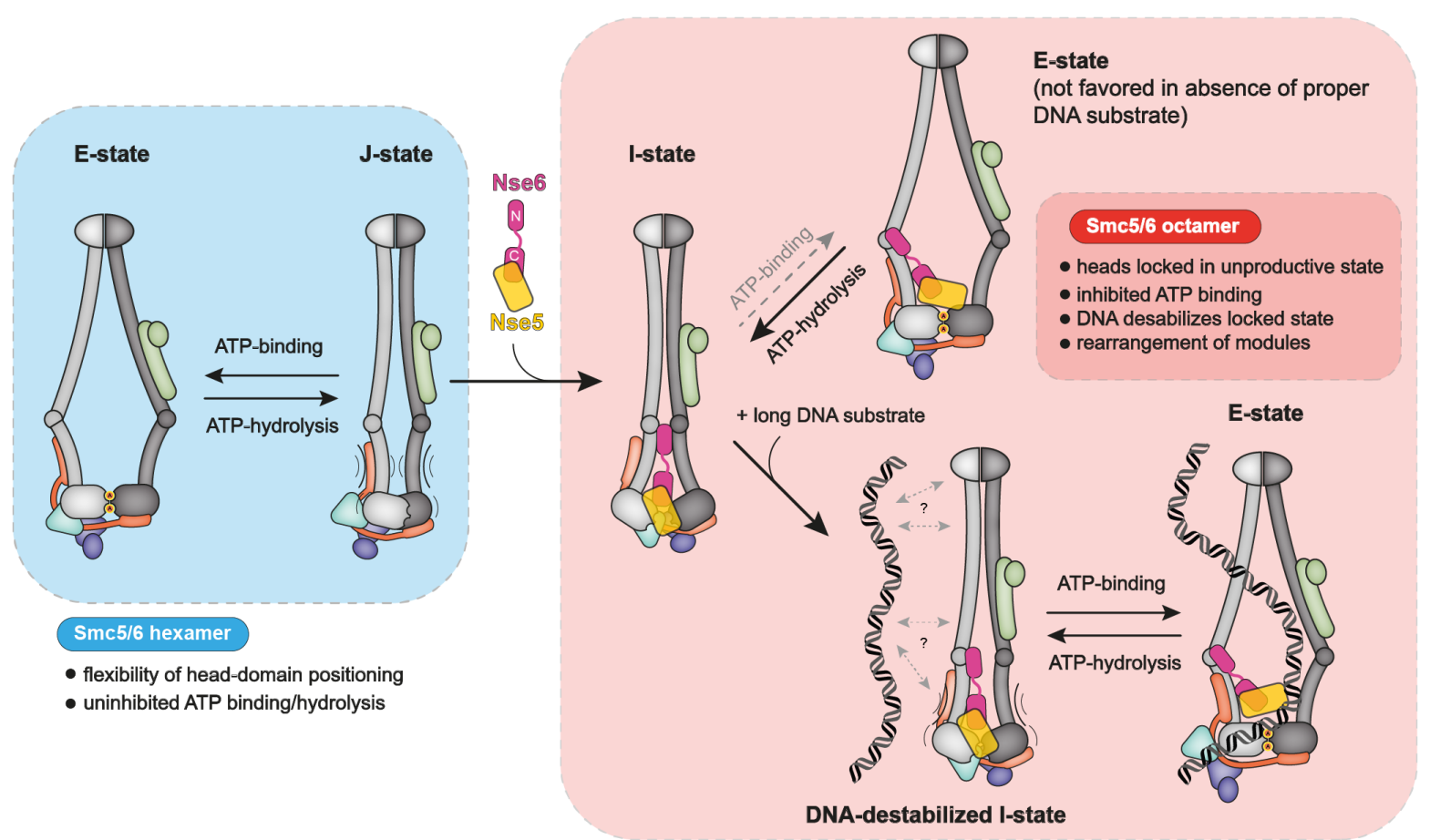

Figure 7. Model for conformational changes in Smc5/6.

hawk proteins, it remains a (remote) possibility that these proteins share a common origin and similar functions.

The Nse1/3/4 module, including the Nse1 ubiquitin ligase-the third enzymatic activity of Smc5/6 - is also directly affected by plasmid DNA binding as judged by our XL-MS data (Fig 6). Multiple inter-domain cross-links of the Nse1/3/4 module to the Smc5 and Smc6 proteins, mostly to the heads, were lost upon ATP and plasmid DNA addition. We postulate that Nse1/3/4 relocates by binding to DNA using the proposed DNA binding residues in Nse3 (Zabrady et al., 2016), possibly assisting to evict Nse5/6 from the heads and if so underscoring the central role of Nse5/6 in regulating the enzymatic activities of the Smc5/6 complex.

Smc5/6 hexamer and octamer showed disparate basal ATP hydrolysis activity and responded distinctly to addition of 40bpDNA

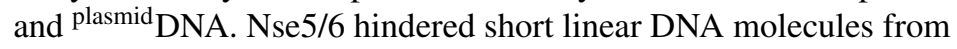
activating the Smc5/6 ATPase, presumably by blocking access to a DNA binding site, possible the head/DNA binding interface. Curi-

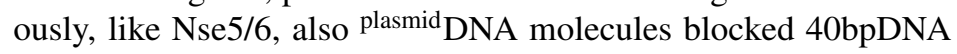
from stimulating ATP hydrolysis. These findings suggest that multiple mechanisms of DNA stimulation exist with one predominating in the hexamer, the other in the octamer. Moreover, only the hexamer exhibited cooperativity in ATP hydrolysis. Clearly, the loader has a major impact on Smc5/6 activity. We thus suspect that Nse5/6 (or Slf1/2) is needed for proper activity of this complex. It will be interesting to compare hexamer and octamer activity in recently reported single-molecule assays (Gutierrez-Escribano et al., 2020; Serrano et al., 2020).

The observed inhibition of the Smc5/6 ATPase by the Nse5/6 loader is in stark contrast to the reported activation of the cohesin ATPase by the cohesin loader, Scc2/4 or NIPBL (Davidson et al., 2019; Petela et al., 2018). If Nse5/6 and Scc2/4 are indeed bona fide loaders for their respective complexes, then their loading mechanisms might be starkly different, apart from the fact that both loader complexes directly influence these SMC complexes at their cores, the ATPase heads. The arms of cohesin, condensin, and the noncanonical bacterial SMC complex MukBEF have been unequivocally shown to fold $180^{\circ}$ at an elbow (Burmann et al., 2019; Lee et al., 2020). The position of the elbow along the arms and its sequence are only poorly conserved across these divergent families of SMC complexes, implying independent emergence. The possible existence of elbows in the arms of yeast Smc5/6 was previously reported, but not without controversy. Here, we found no convincing evidence for the folding of arms in yeast Smc5/6, with similar conclusions recently being drawn for same complex (Yu et al., 2021) and a human Smc5/6 core complex (Serrano et al., 2020). While some XL-MS inter-domain cross-links are consistent with a folded state, these cross-links imply different folding points, more often than not being inconsistent with the predicted discontinuities in the heptad repeat of the Smc5/6 coiled coils (Burmann et al., 2019), presumed to support the arm folding (found one third of the way from the hinge). Together with the display of fully extended particles by electron microscopy, we argue that the unfolded state is predominating in our preparations of complexes and the presence of the inter-domain cross-links rather point to inter-complex interactions or false positives which cannot be excluded due to the false positive rate correction at $1 \%$ employed in the data analysis. Similarly, no obvious indication has been found for a folded state of the ubiquitous bacterial SMC complex Smc-ScpAB (Soh et al., 2015). Curiously, ancestral forms of Smc-ScpAB and of Smc5/6 are thought to be at the root of prokaryotic and eukaryotic SMC complexes, respectively, again suggesting that elbows have emerged independently at least twice (in ancestral MukBEF and in a common ancestor of cohesin/condensin) (Palecek and Gruber, 2015; 
Wells et al., 2017). If these considerations are valid, then the elbow likely provides for optimized SMC activity rather than being required for its core function.

Altogether, we have uncovered a central role of the Nse5/6 'loader' complex in the regulation of the Smc5/6 ATPase. It modulates DNA substrate selection by Smc5/6. With Nse5/6 being specific to the family of Smc5/6 complexes only, we believe the new insights are directly relevant in specifying the unique activities of this complex in genome maintenance and chromosome segregation.

\section{Materials and Methods}

Preparation of DNA substrates Two types of DNA substrates

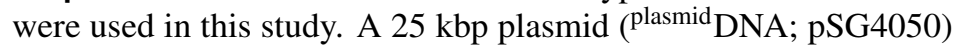
was purified using a NucleoBond Xtra Maxi EF kit (Macherey Nagel) according to the manufacturer's instructions. The plasmid stock had a concentration of $1.5 \mathrm{mg} / \mathrm{ml}$, equivalent to around 90 $\mathrm{nM}$. Linearized plasmid was prepared by incubation of the circular substrate with AgeI restriction enzyme, and the enzyme was afterwards inactivated by heating to $80^{\circ}() \mathrm{C}$ for $20 \mathrm{~min}$. The second type of DNA substrates was a 40 bp duplex (40bpDNA) obtained by annealing of two complementary oligonucleotides (STI699: 5'TTAGTTGTTCGTAGTGCTCGTCTGGCTCTGGATTACCCGC-3', STI700: 5'- GCGGGTAATCCAGAGCCAGACGAGCACTACGAA CAACTAA-3'). This 40bpDNA stock solution was prepared at a concentration of $100 \mu \mathrm{M}$.

Yeast strains. All yeast strains were in the W303 background and were created using standard methods.

YSG0008 (MATa/a, ade2-1, trp1-1, can1-100, leu2-3,112, his3-11,15, ura3, GAL, psi+)

YSG0232 (as YSG0008, but with NSE6/nse6D::KanMx)

YSG0257 (as YSG0008, but with NSE6/NSE6 - 3CTSHis::KanMx)

YSG0259 (as YSG0008, but with NSE6/nse6(86-454) - 3CTSHis::KanMx) YSG0260 (as YSG0008, but with NSE6/nse6(177-454) - 3CTSHis::KanMx) YSG0261 (as YSG0008, but with NSE6/nse6(1-179) - 3CTSHis::KanMx)

Protein expression in E. coli. All proteins and protein complexes described in this manuscript were expressed in E. coli (DE3) Rosetta. Hexameric Smc5/6 complexes were produced from a single plasmid carrying all six subunits, with a C-terminal 3C-Twin-Strep tag on Smc6. The four Nse subunits (Nse1, Nse2, Nse3, Nse4) were combined into a tetracistronic module separated by ribosomal binding sites and expressed under the control of a T7 promoter. Smc6 and Smc5 expression was driven by a T7 and tac promoter, respectively.

For production of Nse5/6 complex several tagged versions were prepared. In all cases the two coding sequences were connected by a ribosomal binding site to create a bicistronic construct (Nse6-RBS-Nse5) driven by a T7 promoter. Affinity tag(s) were added to the N-terminus of Nse6 and/or the C-terminus of Nse5. For pulldowns between Twin-Strep-tagged Smc5/6 hexamer and Nse5/6 dimer a version containing a C-terminal 3C-His(8) tag on Nse5 was used. For ATPase assays, Nse6 carried an N-terminal TwinStrep tag, and Nse5 contained a C-terminal His(8) tag. Reconstitution of octameric complexes was performed with a C-terminally AviTag-3C-TwinStrep-tagged version of Nse5. Crystallization constructs with N-terminally truncated versions of Nse6 carried an N-terminal His(10)-Twin-Strep-3C tag on Nse6. The N-terminal Nse6 fragment used for pulldown assays with the Smc5/6 hexamer was produced with a C-terminal Cysteine Protease Domain (CPD)-His(8) tag.
For all purifications 1 liter of the strain carrying the desired plasmid was grown in $\mathrm{TB}$-medium at $37^{\circ} \mathrm{C}$ to an $\mathrm{OD}(600 \mathrm{~nm})$ of 1.0 and the culture temperature was reduced to $22^{\circ} \mathrm{C}$. Expression was then induced with IPTG at a final concentration of $0.4 \mathrm{mM}$ and allowed to proceed overnight (typically 16 hours).

Purification of the hexameric S. cerevisiae Smc5/6 complex. E. coli cells were harvested by centrifugation and resuspended in 3-4 $\mathrm{x}$ the pellet volume of lysis buffer $(50 \mathrm{mM}$ Tris- $\mathrm{HCl} \mathrm{pH} \mathrm{7.5,} 300 \mathrm{mM} \mathrm{NaCl}, 5$ $\%$ glycerol, $25 \mathrm{mM}$ Imidazole) freshly supplemented with $5 \mathrm{mM}$ DTT, 1 mM PMSF, and 750 units of SM nuclease. All subsequent buffer except the gel-filtration buffer contained $2 \mathrm{mM}$ of DTT. Cells were lysed by sonication on ice with a VS70T tip using a SonoPuls unit (Bandelin) at $40 \%$ output for 15 min with pulsing ( 1 second on / 1 second off), typically yielding a total delivered energy of $15 \mathrm{~kJ}$. The lysate was clarified by centrifugation (40000 $\mathrm{g}$ for $30 \mathrm{~min}$ ) and the supernatant applied onto a $5 \mathrm{ml}$ StrepTrap column (GE Healthcare). After washing with 10 column volumes (CV) of lysis buffer the bound material was eluted with $4 \mathrm{CV}$ of lysis buffer supplemented with $2.5 \mathrm{mM}$ desthiobiotin and fractions of $1.5 \mathrm{ml}$ were collected. Fractions containing the complex were then applied onto a $5 \mathrm{ml}$ HiTrap Heparin column (GE Healthcare), and after washing with $5 \mathrm{CV}$ of lysis buffer the bound material was eluted with $4 \mathrm{CV}$ of Heparin elution buffer $(20 \mathrm{mM}$ Tris $\mathrm{pH} 7.5,1000 \mathrm{mM} \mathrm{NaCl}, 2 \mathrm{mM}$ DTT). Fractions of $1.5 \mathrm{ml}$ were collected and those containing the target were concentrated with Amicon Ultra centrifugal filter units (50 kDa cutoff; Millipore) to a final concentration of around 8 $\mathrm{mg} / \mathrm{ml}(20-25 \mu \mathrm{M})$. The protein was then injected onto a Superose6 10/300 GL size-exclusion chromatography (SEC) column. The standard SEC-buffer contained $20 \mathrm{mM}$ Tris- $\mathrm{HCl} \mathrm{pH} \mathrm{7.5,} 250 \mathrm{mM} \mathrm{NaCl}$, and $1 \mathrm{mM}$ TCEP. For experiments involving lysine crosslinking a buffer containing $20 \mathrm{mM}$ Hepes$\mathrm{KOH} \mathrm{pH} 7.5$ was used instead of Tris. Fractions containing the complex were concentrated to around $5 \mu \mathrm{M}$ and snap-frozen in small (30-50 $\mu \mathrm{l})$ aliquots for subsequent experiments.

Purification of full-length Nse5/6 complexes. Lysates were prepared as described for the Smc5/6 hexameric complex, and the same lysis buffer was used with the exception that $5 \mathrm{mM}$ DTT was replaced by 5 $\mathrm{mM}$ beta-mercapto ethanol. For the version with a C-terminal 3C-His(8) tag on Nse5, the lysate was first loaded onto a $5 \mathrm{ml}$ HisTrap column (GEHealthcare), and after washing with $5 \mathrm{CV}$ of lysis buffer and $5 \mathrm{CV}$ of buffer A ( $20 \mathrm{mM}$ Tris- $\mathrm{HCl} \mathrm{pH} \mathrm{7.5,} 100 \mathrm{mM} \mathrm{NaCl}, 5 \mathrm{mM}$ beta-mercapto ethanol) the bound material was eluted with a $10 \mathrm{CV}$ gradient from buffer A to the same buffer supplemented with $500 \mathrm{mM}$ Imidazole $\mathrm{pH}$ 7.5. Fractions containing the complex at reasonable purity were loaded onto a $5 \mathrm{ml}$ HiTrap Heparin column (GE Healthcare), and the bound protein was eluted with a gradient from buffer A to buffer B (20 mM Tris- $\mathrm{HCl}$ pH 7.5, $1000 \mathrm{mM} \mathrm{NaCl}, 2$ mM DTT). Fractions with protein at sufficient purity were concentrated and injected onto a Superdex200 Increase 10/300 GL SEC column in a buffer containing $20 \mathrm{mM}$ Tris $\mathrm{pH} 7.5,300 \mathrm{mM} \mathrm{NaCl}$, and $1 \mathrm{mM}$ TCEP. The final protein was concentrated to around $20-30 \mu \mathrm{M}$ and snap-frozen in small (20$30 \mu \mathrm{l})$ aliquots.

For the version that contained an N-terminal Twin-Strep tag on Nse6 and a C-terminal His(8) tag on Nse5 the purification was performed as described for the Nse6/Nse5-3C-His complex, except that the elution from the HisTrap column was loaded onto a $5 \mathrm{ml}$ StrepTrap column and bound material was eluted with buffer A supplemented with $2.5 \mathrm{mM}$ desthiobiotin. All subsequent steps (Heparin and SEC) were identical.

The version containing a C-terminal AviTag-3C-Twinstrep tag on Nse5 the lysate was loaded onto a $5 \mathrm{ml}$ StrepTrap column and eluted with buffer A containing $2.5 \mathrm{mM}$ desthiobiotin. The elution was then loaded on a Heparin and SEC column as described for the other complexes.

For crystallization constructs with N-terminally His(10)-TwinStrep-3C 
tags the lysate the purification was identical to the TwinStrep-Nse6/Nse5-His version, except that before SEC the tag was removed by incubation with HRV-3C protease (overnight at $4^{\circ} \mathrm{C}$ ) and that a different SEC buffer $(20 \mathrm{mM}$ Tris pH 7.5, $500 \mathrm{mM} \mathrm{NaCl}, 1 \mathrm{mM}$ TCEP) was used.

Nse6(1-179)-CPDHis protein was purified as described for the Nse6/Nse5$3 \mathrm{C}$-His version.

\section{Reconstitution of octameric complexes by size-exclusion chro-} matography. Purified Smc5/6 hexamer (with a C-terminal 3C-TwinStrep tag on Smc6) and Nse5/6 dimers (various versions) were mixed in a total volume of $500 \mu \mathrm{l}$ with a $1.5 \mathrm{x}$ molar excess of Nse $5 / 6$. This mixture was then subjected to SEC using either a Superose6 Increase 10/300GL or a Superose6 Increase 3.2/300 column. For most experiments the Nse6/Nse5-3C-His(8) complex was used, the tags were not removed, and the SEC buffer contained $20 \mathrm{mM}$ Tris- $\mathrm{HCl} \mathrm{pH}$ 7.5, $250 \mathrm{mM} \mathrm{NaCl}$, and $1 \mathrm{mM}$ TCEP. For lysine crosslinking analysis, the hexamer was mixed with Nse6/Nse5-AviTag-3CTwinStrep, the TwinStrep-tags were removed by incubation with HRV-3C protease overnight at $4^{\circ} \mathrm{C}$ before SEC, and an amine-free SEC buffer $(10 \mathrm{mM}$ Hepes-KOH pH 7.5, $250 \mathrm{mM} \mathrm{NaCl}, 1 \mathrm{mM}$ TCEP) was used. Fractions were analysed by SDS-Page and those containing pure octameric holocomplex were concentrated to around $5 \mu \mathrm{M}$, and snap-frozen in aliquots for subsequent use.

Pulldown experiments. For interaction analyses between Nse5/6 complexes with TwinStrep-tagged Smc5/6 hexamer, the Nse5/6 complexes (or Nse6N-CPDHis) were diluted to $1 \mu \mathrm{M}$ in a total volume of $250 \mu \mathrm{l}$ with buffer (10 mM Hepes-KOH pH 7.5, $150 \mathrm{mM}$ potassium acetate, $2 \mathrm{mM} \mathrm{MgCl} 2$, $20 \%$ glycerol) and an input sample was removed and boiled for 5 minutes after mixing with 2 x SDS gel loading dye. StrepTactin Sepharose High Performance resin (GE Healthcare; $20 \mu \mathrm{l}$ resin per pulldown) was either incubated with only $250 \mu \mathrm{l}$ buffer, or with the same buffer containing 0.5 $\mu \mathrm{M}$ TwinStrep-tagged Smc5/6 hexamer. After $1 \mathrm{~h}$ incubation at $4{ }^{\circ} \mathrm{C}$ on a rotating wheel the resin was collected by centrifugation $(2 \mathrm{~min}$ at $700 \mathrm{~g}$ ) and washed twice with $500 \mu \mathrm{l}$ of buffer to remove unbound hexamer. Pre-diluted Nse $5 / 6$ complexes were then incubated with either empty or loaded resin for $1 \mathrm{~h}$ at $4^{\circ} \mathrm{C}$ on a rotating wheel, and afterwards the resin was collected by centrifugation and washed twice with $1 \mathrm{ml}$ of buffer. Bound material was eluted with buffer supplemented with $2.5 \mathrm{mM}$ desthiobiotin and analyzed by SDS-Page.

Limited proteolysis of the Nse5/6 complex . The complex used for analysis by limited proteolysis was the Nse6/Nse5-3C-His(8) complex at a concentration of $14 \mathrm{mg} / \mathrm{ml}(120 \mu \mathrm{M})$. For the time course shown in Fig $2 \mathrm{~B} 19$ $\mu \mathrm{l}$ of this protein were combined with $1 \mu \mathrm{l}$ of trypsin (Sigma; $1 \mathrm{mg} / \mathrm{ml}$ ) and the mixture was incubated at RT. At the indicated time points $1 \mu \mathrm{l}$ aliquots were removed, mixed with 1 x SDS loading dye and boiled for 5 minutes. All time points were then analysed by SDS-Page, and bands of interested were analysed by LC-MS/MS.

LC-MS/MS analyses of Nse5/6 proteolytic fragments. In-gel proteolytic cleavage with sequencing grade trypsin (Promega) was performed as described (Shevchenko et al., 2006). The peptides from the digestion were dried and redissolved in $0.05 \%$ trifluoroacetic acid, $2 \%$ acetonitrile for analysis with liquid chromatography coupled with tandem mass spectrometry. Samples were injected on a Q-Exactive Plus mass spectrometer interfaced via a nano EASY-Spray source to an Ultimate 3000 RSLCnano HPLC system (Thermo Scientific). After loading onto a trapping microcolumn Acclaim PepMap100 C 18 (20 mm x $100 \mu \mathrm{m}$ ID, $5 \mu \mathrm{m}$, Thermo Scientific), peptides were separated on a reversed-phase Easy Spray $\mathrm{C}_{18}$ column $(50 \mathrm{~cm}$ x $75 \mu \mathrm{m}$ ID, $2 \mu \mu \mathrm{m}, 100 \AA$, Thermo Scientific). A 4-76\% acetonitrile gradient in $0.1 \%$ formic acid (total time 140 minutes) was used for the separation with a flow of $250 \mathrm{nl} /$ minute. Full MS survey scans were performed at 70'000 resolution.
In data-dependent acquisition controlled by Xcalibur 4.0 software (Thermo Scientific), the 10 most intense multiply charged precursor ions detected in the full MS survey scan were selected for higher energy collision-induced dissociation (HCD, normalized collision energy NCE=27\%) and analyzed in the orbitrap at 17'500 resolution. The window for precursor isolation was of $1.5 \mathrm{~m} / \mathrm{z}$, units around the precursor and selected fragments were excluded for $60 \mathrm{~s}$ from further analysis.

MS/MS data were analyzed using Mascot 2.7 (Matrix Science, London, UK) set up to search the yeast proteome in the UniProt database (www.uniprot.org, reference proteome of Saccharomyces cerevisiae (strain ATCC 204508 / S288c), January 2019 version: 6'049 sequences). Trypsin (cleavage at $\mathrm{K}, \mathrm{R}$ ) was used as the enzyme definition, allowing 2 missed cleavages. Mascot was searched with a parent ion tolerance of $10 \mathrm{ppm}$ and a fragment ion mass tolerance of $0.02 \mathrm{Da}$. Iodoacetamide derivative of cysteine was specified in Mascot as a fixed modification. N-terminal acetylation of protein and oxidation of methionine were specified as variable modifications.

Cross-linking mass-spectrometry (XL-MS) experiments. Protein samples were diluted with either ATPase buffer (10 mM Hepes-KOH pH 7.5, $150 \mathrm{mM}$ potassium acetate, $20 \%$ glycerol, $2 \mathrm{mM} \mathrm{MgCl} 2$ ) or salt buffer (20 $\mathrm{mM}$ Hepes- $\mathrm{KOH} \mathrm{pH} 7.5,250 \mathrm{mM} \mathrm{NaCl}$ ) to a final concentration of $1.6 \mu \mathrm{M}$ in $125 \mu \mathrm{l}$. For cross-linking in the presence of ligands $2 \mathrm{mM}$ ATP and $16 \mathrm{nM}$ plasmid DNA ( $25 \mathrm{kbp}$ ) were added and the mixture incubated for 10 minutes at RT. This ratio of protein: ${ }^{\text {plasmid }}$ DNA corresponds to around 250 bp dsDNA per complex and thus matches the conditions used in ATPase assays. PhoX crosslinker ( $5 \mathrm{mM}$ stock in DMSO) was added to a final concentration of $0.25 \mathrm{mM}$ and the mixture was incubated for 20 minutes at RT. The reactions were then quenched by addition of Tris- $\mathrm{HCl} \mathrm{pH} 7.5$ (1M stock) to a final concentration of $20 \mathrm{mM}$ and samples were snap-frozen.

To denature the cross-linked proteins ( $125 \mu \mathrm{g}$ in each sample), $4 \mathrm{M}$ Urea and $50 \mathrm{mM}$ Tris was added and the samples were ultrasonicated two times for 2 minutes with 0.5 -second pulses (50\% intensity) and 0.2 -second pauses (Sonopuls, Bandelin). Next, $1 \mathrm{mM} \mathrm{MgCl} 2$ and $1 \%$ benzonase was added and the mixture was incubated for $1 \mathrm{~h}$ at $37^{\circ} \mathrm{C}$. For reduction and alkylation of the proteins, $40 \mathrm{mM}$ 2-cloroacetamide (CAA, Sigma-Aldrich) and $10 \mathrm{mM}$ tris(2-carboxyethyl)phosphine (TCEP; Thermo Fisher Scientific), and 100 $\mathrm{mM}$ Tris at $\mathrm{pH} 8.0$ was added. After incubation for $20 \mathrm{~min}$ at $37{ }^{\circ} \mathrm{C}$, the samples were diluted 1:2 with MS grade water (VWR). Proteins were digested overnight at $37^{\circ} \mathrm{C}$ by addition of $3 \mu \mathrm{g}$ trypsin (Promega) and $2 \mu \mathrm{g} \mathrm{LysC}$ (Promega). After digestion, the solution was acidified with trifluoroacetic acid (TFA; Merck) to a final concentration of $1 \%$ and a $\mathrm{pH}$ of $; 2$. The peptide mixtures were purified via Sep-Pak $\mathrm{C}_{18} 1 \mathrm{cc}$ vacuum cartridges (Waters) and the elution finally vacuum dried. Cross-linked peptides were enriched with Fe(III)-NTA cartridges (Agilent Technologies; Santa Clara, Ca) using the AssayMAP Bravo Platform (Agilent Technologies; Santa Clara, Ca) in an automated fashion (Post et al., 2017; Steigenberger et al., 2019). Cartridges were primed at a flow rate of $100 \mu \mathrm{L} /$ min with $250 \mu \mathrm{L}$ of priming buffer $(0.1 \%$ TFA, $99.9 \% \mathrm{ACN})$ and equilibrated at a flow-rate of $50 \mu \mathrm{L} / \mathrm{min}$ with $250 \mu \mathrm{L}$ of loading buffer $(0.1 \%$ TFA, $80 \% \mathrm{ACN})$. The flow-through was collected into a separate plate. Dried samples were dissolved in $200 \mu \mathrm{L}$ of loading buffer and loaded at a flow-rate of $5 \mu \mathrm{L} / \mathrm{min}$ onto the cartridge. Cartridges were washed with $250 \mu \mathrm{L}$ of loading buffer at a flow-rate of 20 $\mu \mathrm{L} / \mathrm{min}$ and cross-linked peptides were eluted with $35 \mu \mathrm{L}$ of $10 \%$ ammonia directly into $35 \mu \mathrm{L}$ of $10 \%$ formic acid. Samples were dried down and stored at $-20{ }^{\circ} \mathrm{C}$ prior to further use. Before to LC-MS/MS analysis, the samples were resuspended in $0.1 \%$ formic acid.

Enriched peptides were loaded onto a 30-cm analytical column (inner diameter: 75 microns; packed in-house with ReproSil-Pur $\mathrm{C}_{18}$-AQ 1.9-micron beads, Dr. Maisch GmbH) by the Thermo Easy-nLC 1000 (Thermo Fisher Scientific) with buffer A $(0.1 \%$ (v/v) Formic acid) at $400 \mathrm{nl} / \mathrm{min}$. The analytical column was heated to $60^{\circ} \mathrm{C}$. Using the nanoelectrospray interface, eluting 
peptides were sprayed into the benchtop Orbitrap Q Exactive HF (Thermo Fisher Scientific) (Hosp et al., 2015; Scheltema et al., 2014). As gradient, the following steps were programmed with increasing addition of buffer B ( $80 \%$ Acetonitrile, $0.1 \%$ Formic acid): linear increase from 8 to $30 \%$ over 60 minutes, followed by a linear increase to $60 \%$ over 5 minutes, a linear increase to $95 \%$ over the next 5 minutes, and finally maintenance at $95 \%$ for another 5 minutes. The mass spectrometer was operated in data-dependent mode with survey scans from $\mathrm{m} / \mathrm{z}, 300$ to 1650 Th (resolution of 60 '000 at $\mathrm{m} / \mathrm{z}$ $=200 \mathrm{Th}$ ), and up to 15 of the most abundant precursors were selected and fragmented using stepped Higher-energy C-trap Dissociation (HCD with a normalized collision energy of value of 19, 27, 35) (Olsen et al., 2007). The MS2 spectra were recorded with dynamic $\mathrm{m} / \mathrm{z}$, range (resolution of 30'000 at $m / z=200 \mathrm{Th}$ ). AGC target for MS1 and MS2 scans were set to 3E6 and 1E5 respectively within a maximum injection time of 100 and $60 \mathrm{~ms}$ for the MS1 and MS2 scans respectively. Charge state 2 was excluded from fragmentation to enrich the fragmentation scans for cross-linked peptide precursors.

The acquired raw data were processed using Proteome Discoverer (version 2.5.0.400) with the XlinkX/PD nodes integrated (Klykov et al., 2018). To identify the crosslinked peptide pairs, a database search was performed against a FASTA containing the sequences of the proteins under investigation. Cysteine carbamidomethylation was set as fixed modification and methionine oxidation and protein $\mathrm{N}$-term acetylation were set as dynamic modifications. Trypsin/P was specified as protease and up to two missed cleavages were allowed. Furthermore, identifications were only accepted with a minimal score of 40 and a minimal delta score of 4 . Otherwise, standard settings were applied. Filtering at $1 \%$ false discovery rate (FDR) at peptide level was applied through the XlinkX Validator node with setting simple.

Crystallization of the Nse6(177-C)/Nse5 complex. A selenomethionine substituted complex was prepared following a methionine biosynthesis feedback inhibition protocol (Burmann et al., 2013) and concentrated to $18 \mathrm{mg} / \mathrm{ml}$. Crystals were grown at $19^{\circ} \mathrm{C}$ by hanging-drop vapor diffusion from $2 \mu \mathrm{L}$ drops formed by equal volumes of protein and of crystallization solution (12\% (w/v) PEG 3350, 8\% (v/v) 0.3 M Sodium malonate $\mathrm{pH} 7.5$ ). Prior to flash freezing in liquid nitrogen, the crystals were briefly soaked in mother liquor containing $32 \%$ (v/v) ethylene glycol.

Data collection and crystal structure determination. A singlewavelength anomalous diffraction experiment from selenium atoms (S-SAD) was performed at the macromolecular crystallography beamline X10SA (PXII) at the Swiss Light Source (Villigen, Switzerland). On a single crystal, a $360^{\circ}$ data set was collected at $100 \mathrm{~K}$ at a wavelength of $0.9792 \AA$. The data analysis showed anisotropic diffraction in one direction. The data were processed using XDS and scaled and merged with XSCALE (Kabsch, 2010). Substructure determination and phasing were performed with SHELXC/D/E (Sheldrick, 2010) using the HKL2MAP interface (Pape and Schneider, 2004). The successful SHELXD substructure solution, in a search for 13 selenium sites, had a Ccall and a Ccweak of 49.9 and 22.5, respectively. Density modification resulted in a clear separation of hands. An initial model was built automatically with BUCCANEER (Cowtan, 2006). The model was completed by iterative cycles of model building in COOT (Emsley and Cowtan, 2004). Followed by refinement in PHENIX (Adams et al., 2010).

Calculation of Nse5 and Nse6 surface conservation. Separate pdb-files for each protein were submitted to the ConSurf Server (Ashkenazy et al., 2016; Landau et al., 2005) and a multiple sequence alignment was generated automatically with standard settings, allowing max. $95 \%$ identity between sequences and min. $35 \%$ identity for homologs. The outputs were visualized in PyMol and colors were assigned to individual residues using the consurf new script.
Thermofluor buffer screening. The Smc5/6 hexamer showed a tendency to aggregate/precipitate in buffers with low ionic strength. For DNAstimulated ATPase activity assays we needed to find a buffer which is compatible with both protein stability and stable interaction with DNA substrates. As basic components we chose $10 \mathrm{mM}$ Hepes-KOH ph7.5, $2 \mathrm{mM} \mathrm{MgCl}_{2}$, and $150 \mathrm{mM}$ potassium acetate, and used Thermofluor measurements in the presence of various additives such as detergents (NP40, DDM, Tween20, TritonX-100), sugars (Glucose, Sucrose), or macromolecular crowding reagents (Glycerol, ethylene glycol, PEG 400). $2 \mu \mathrm{L}$ protein solutions $(0.1$ $\mathrm{mg} / \mathrm{mL}$ ) and $18 \mu \mathrm{L}$ of buffer containing $10 \mathrm{X}$ of Sypro Orange (Invitrogen) were added to the wells of a 96-well. The plate was sealed and heated in a real-time PCR system (Light Cycler 480, Roche diagnostic) from $20^{\circ} \mathrm{C}$ to $80^{\circ} \mathrm{C}$ in increments of $0.5^{\circ} \mathrm{C} /$ minute. Fluorescence changes were monitored simultaneously. The wavelengths for excitation and emission were 498 and $610 \mathrm{~nm}$, respectively. A simplified unfolding model (Chari et al., 2015) was used to fit the fluorescence data after normalization and obtain the temperature midpoint for the protein unfolding transition. The composition of the buffer chosen based on this analysis was $10 \mathrm{mM}$ Hepes-KOH pH 7.5, 150 $\mathrm{mM}$ potassium acetate, $2 \mathrm{mM} \mathrm{MgCl} 2$, and $20 \%$ glycerol (ATPase buffer).

ATPase assays. ATPase activity measurements were done by a pyruvate kinase/lactate dehydrogenase coupled reaction at $25^{\circ} \mathrm{C}$ in ATPase buffer (10 mM Hepes-KOH pH 7.5, $150 \mathrm{mM}$ potassium acetate, $2 \mathrm{mM} \mathrm{MgCl}_{2}$, $20 \%$ glycerol). ADP accumulation was monitored for $1 \mathrm{~h}$ by measuring absorbance changes at $340 \mathrm{~nm}$ caused by NADH oxidation in a Synergy Neo Hybrid Multi-Mode Microplate reader. The $100 \mu$ reactions contained 1 mM NADH, 3 mM Phosphoenol pyruvic acid, 100 U Pyruvate kinase, $20 \mathrm{U}$ Lactate dehydrogenase and the indicated concentrations of ATP and DNA substrates. The final concentration of Smc5/6 hexamer in the assay was 150 $\mathrm{nM}$, except for the experiments with protein titration shown in Fig. S4B and S4C. The purified Twin-Strep-Nse6/Nse5-His(8) complex was added in two-fold molar excess to ensure complete formation of the octameric holocomplex. DNA substrates were added at a concentration corresponding to $250 \mathrm{bp}$ DNA per complex. Results from these assays were analyzed using the GraphPad Prism software.

Site-specific BMOE crosslinking. Smc5/6 hexamers with or without indicated reporter-cysteines were diluted to a final concentration of $0.5 \mu \mathrm{M}$ in ATPase buffer in a total volume of $40 \mu \mathrm{l}$. In reactions containing the Nse 5/6 dimer, this complex was added in a $1.25 \mathrm{x}$ molar excess $(0.625$ $\mu \mathrm{M})$. Indicated reactions contained ATP ( $2 \mathrm{mM}$ final concentration), and/or

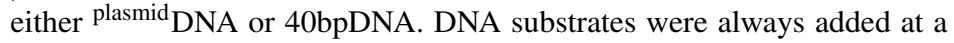
concentration corresponding to around 250 bp per Smc5/6 complex, which corresponded to $5 \mathrm{nM}$ of plasmid DNA and $3.2 \mu \mathrm{M}$ of $40 \mathrm{bp}$ oligonucleotides. Protein and substrates were incubated for $10 \mathrm{~min}$ at RT after mixing, and BMOE was then added at a final concentration of $1 \mathrm{mM}$. After 45 seconds incubation beta-mercapto ethanol was added at a concentration of $14 \mathrm{mM}$ to stop the reaction. Samples were mixed with SDS gel-loading dye, heated to $80^{\circ} \mathrm{C}$ for $15 \mathrm{~min}$, and then analysed on Novex WedgeWell 4-12\% TrisGlycine Gels (Invitrogen). Gels were fixed for $1-2 \mathrm{~h}$ in gel fixing solution (50\% ethanol, $10 \%$ acetic acid) and stained overnight using Coomassie staining solution $(50 \%$ methanol, $10 \%$ acetic acid, $1 \mathrm{mg} / \mathrm{ml}$ Coomassie Brilliant Blue R-250). Gels were destained in destaining solution (50\% methanol, $10 \%$ acetic acid), and then rehydrated and stored in $5 \%$ acetic acid. Quantification of bands in scanned gel images was done using Fiji (Schindelin et al., 2012).

Electron Microscopy. $\quad 4 \mu \mathrm{l}$ peak fractions at a final Abs280nm of $\sim 0.3$ ( $1.3 \mu \mathrm{M})$ were applied to glow discharged $(2.2 \times 10-1 \mathrm{mbar}$ for $20 \mathrm{sec})$ Quantifoil holey carbon grids (R2/1, 200 mesh, Quantifoil). The grids were plunge vitrified into a liquid ethane/propane mix using a Vitrobot Mark IV at $4{ }^{\circ} \mathrm{C}$ and $95 \%$ humidity. Cryo-EM data were collected on a FEI Talos 
Arctica microscope operated at $200 \mathrm{kV}$, equipped with a FEI Falcon 3EC direct detector operating in integrating mode. A total of 2362 movies were recorded at a nominal magnification of $72,000 \mathrm{x}$ that corresponds to 1.997 $\AA$ /pixel at the specimen level using FEI EPU. The total exposure of 89.6 e- $/ \AA^{2}$ at the specimen level was evenly distributed over 40 frames during $4 \mathrm{~s}$. The preset target defocus range was 0.5 to $3.5 \mu \mathrm{m}$.

The RELION-3.0 implementation of MotionCor2 (Zheng et al., 2017) was used to correct for beam-induced sample motions and radiation damage. The summed and dose-weighted micrographs were used for further processing. Particles were selected using Gautomatch (http://www.mrclmb.cam.ac.uk/kzhang/Gautomatch/). CTF parameters were determined using Gctf (Zhang, 2016). The 766'170 initially picked particle candidates were subjected to several rounds of template-free, unsupervised 2D classification in RELION-3.0 (Kimanius et al., 2016; Zivanov et al., 2018). This resulted in the $2 \mathrm{D}$ class averages shown in Fig 1D.

\section{Acknowledgments}

We thank members of the Gruber lab for comments on the manuscript, the Protein Analysis Facility (PAF) at FBM-UNIL for the identification of Nse5 and Nse6 fragments, the crystallization facility at the MPI of Biochemistry for assistance with crystal screening/optimization, and the staff at the Swiss Light Source (SLS) for help with data collection. We are grateful to Serge Pelet and the Pelet lab for helpful advice and for sharing materials and reagents for genetic engineering in yeast. This work was supported by the Swiss National Science Foundation (310030L_170242), the European Research Council (Horizon 2020 ERC CoG 724482) to S.G, and the German Research Foundation (DFG RA2941/1-1) to M.R. Additional support came from the Netherlands Organisation for Scientific Research (NWO) research program TA with project number 741.018.201 and the European Union Horizon 2020 program INFRAIA project Epic-XS (Project 823839) to R.A.S.

\section{References}

1. Adams, P.D., Afonine, P.V., Bunkoczi, G., Chen, V.B., Davis, I.W., Echols, N., Headd, J.J., Hung, L.W., Kapral, G.J., Grosse-Kunstleve, R.W., et al. (2010). PHENIX: a comprehensive Python-based system for macromolecular structure solution. Acta Crystallogr D Biol Crystallogr 66, 213-221.

2. Adamus, M., Lelkes, E., Potesil, D., Ganji, S.R., Kolesar, P., Zabrady, K., Zdrahal, Z., and Palecek, J.J. (2020). Molecular Insights into the Architecture of the Human SMC5/6 Complex. J Mol Biol 432, 3820-3837.

3. Andrews, E.A., Palecek, J., Sergeant, J., Taylor, E., Lehmann, A.R., and Watts, F.Z. (2005). Nse2, a component of the Smc5-6 complex, is a SUMO ligase required for the response to DNA damage. Mol Cell Biol 25, 185-196.

4. Aragon, L. (2018). The Smc5/6 Complex: New and Old Functions of the Enigmatic Long-Distance Relative. Annu Rev Genet 52, 89-107.

5. Ashkenazy, H., Abadi, S., Martz, E., Chay, O., Mayrose, I., Pupko, T., and Ben-Tal, N. (2016). ConSurf 2016: an improved methodology to estimate and visualize evolutionary conservation in macromolecules. Nucleic Acids Res 44, W344-350.

6. Burmann, F., Lee, B.G., Than, T., Sinn, L., O’Reilly, F.J., Yatskevich, S., Rappsilber, J., Hu, B., Nasmyth, K., and Lowe, J. (2019). A folded conformation of MukBEF and cohesin. Nat Struct Mol Biol 26, 227-236.

7. Burmann, F., Shin, H.C., Basquin, J., Soh, Y.M., Gimenez-Oya, V., Kim, Y.G., Oh, B.H., and Gruber, S. (2013). An asymmetric SMCkleisin bridge in prokaryotic condensin. Nat Struct Mol Biol 20, 371-379.
8. Bustard, D.E., Ball, L.G., and Cobb, J.A. (2016). Non-Smc element 5 (Nse5) of the Smc5/6 complex interacts with SUMO pathway components. Biol Open 5, 777-785.

9. Bustard, D.E., Menolfi, D., Jeppsson, K., Ball, L.G., Dewey, S.C., Shirahige, K., Sjogren, C., Branzei, D., and Cobb, J.A. (2012). During replication stress, non-SMC element 5 (NSE5) is required for Smc5/6 protein complex functionality at stalled forks. J Biol Chem 287, 11374-11383.

10. Chapard, C., Jones, R., van Oepen, T., Scheinost, J.C., and Nasmyth, K. (2019). Sister DNA Entrapment between Juxtaposed Smc Heads and Kleisin of the Cohesin Complex. Mol Cell 75, 224-237 e225.

11. Chari, A., Haselbach, D., Kirves, J.M., Ohmer, J., Paknia, E., Fischer, N., Ganichkin, O., Moller, V., Frye, J.J., Petzold, G., et al. (2015). ProteoPlex: stability optimization of macromolecular complexes by sparse-matrix screening of chemical space. Nat Methods 12, 859-865.

12. Copsey, A., Tang, S., Jordan, P.W., Blitzblau, H.G., Newcombe, S., Chan, A.C., Newnham, L., Li, Z., Gray, S., Herbert, A.D., et al. (2013). Smc5/6 coordinates formation and resolution of joint molecules with chromosome morphology to ensure meiotic divisions. PLoS Genet 9, e1004071.

13. Cowtan, K. (2006). The Buccaneer software for automated model building. 1. Tracing protein chains. Acta Crystallogr D Biol Crystal$\operatorname{logr} 62,1002-1011$.

14. Cuylen, S., Metz, J., and Haering, C.H. (2011). Condensin structures chromosomal DNA through topological links. Nat Struct Mol Biol 18, 894-901.

15. Cuylen, S., Metz, J., Hruby, A., and Haering, C.H. (2013). Entrapment of chromosomes by condensin rings prevents their breakage during cytokinesis. Dev Cell 27, 469-478.

16. Davidson, I.F., Bauer, B., Goetz, D., Tang, W., Wutz, G., and Peters, J.M. (2019). DNA loop extrusion by human cohesin. Science 366, 1338-1345.

17. Diebold-Durand, M.L., Lee, H., Ruiz Avila, L.B., Noh, H., Shin, H.C., Im, H., Bock, F.P., Burmann, F., Durand, A., Basfeld, A., et al. (2017). Structure of Full-Length SMC and Rearrangements Required for Chromosome Organization. Mol Cell 67, 334-347 e335.

18. Dong, X., Biswas, A., Suel, K.E., Jackson, L.K., Martinez, R., Gu, H., and Chook, Y.M. (2009). Structural basis for leucine-rich nuclear export signal recognition by CRM1. Nature 458, 1136-1141.

19. Doyle, J.M., Gao, J., Wang, J., Yang, M., and Potts, P.R. (2010). MAGE-RING protein complexes comprise a family of E3 ubiquitin ligases. Mol Cell 39, 963-974.

20. Duan, X., Sarangi, P., Liu, X., Rangi, G.K., Zhao, X., and Ye, H. (2009a). Structural and functional insights into the roles of the Mms21 subunit of the Smc5/6 complex. Mol Cell 35, 657-668.

21. Duan, X., Yang, Y., Chen, Y.H., Arenz, J., Rangi, G.K., Zhao, X., and Ye, H. (2009b). Architecture of the Smc5/6 Complex of Saccharomyces cerevisiae Reveals a Unique Interaction between the Nse5-6 Subcomplex and the Hinge Regions of Smc5 and Smc6. J Biol Chem 284, 8507-8515.

22. Emsley, P., and Cowtan, K. (2004). Coot: model-building tools for molecular graphics. Acta Crystallogr D Biol Crystallogr 60, 21262132.

23. Etheridge, T.J., Villahermosa, D., Irmisch, A., Watson, A.T., Herbert, A., Dang, H.Q., Osborne, M.A., Oliver, A.W., Carr, A.M., and Murray, J.M. (2020). Single-molecule live cell imaging of the Smc5/6 DNA repair complex. 2020.2006.2019.148106.

24. Ganji, M., Shaltiel, I.A., Bisht, S., Kim, E., Kalichava, A., Haering, C.H., and Dekker, C. (2018). Real-time imaging of DNA loop extrusion by condensin. Science 360, 102-105. 
25. Gligoris, T.G., Scheinost, J.C., Burmann, F., Petela, N., Chan, K.L., Uluocak, P., Beckouet, F., Gruber, S., Nasmyth, K., and Lowe, J. (2014). Closing the cohesin ring: structure and function of its Smc3kleisin interface. Science 346, 963-967.

26. Gutierrez-Escribano, P., Hormeno, S., Madariaga-Marcos, J., SoleSoler, R., O’Reilly, F.J., Morris, K., Aicart-Ramos, C., Aramayo, R., Montoya, A., Kramer, H., et al. (2020). Purified Smc5/6 Complex Exhibits DNA Substrate Recognition and Compaction. Mol Cell 80, 1039-1054 e1036.

27. Haering, C.H., and Gruber, S. (2016). SnapShot: SMC Protein Complexes Part I. Cell 164, 326-326 e321.

28. Haering, C.H., Schoffnegger, D., Nishino, T., Helmhart, W., Nasmyth, K., and Lowe, J. (2004). Structure and stability of cohesin's Smc1kleisin interaction. Mol Cell 15, 951-964.

29. Hassler, M., Shaltiel, I.A., and Haering, C.H. (2018). Towards a Unified Model of SMC Complex Function. Curr Biol 28, R1266R1281.

30. Higashi, T.L., Eickhoff, P., Sousa, J.S., Locke, J., Nans, A., Flynn, H.R., Snijders, A.P., Papageorgiou, G., O'Reilly, N., Chen, Z.A., et al. (2020). A Structure-Based Mechanism for DNA Entry into the Cohesin Ring. Mol Cell 79, 917-933 e919.

31. Hirano, M., Anderson, D.E., Erickson, H.P., and Hirano, T. (2001). Bimodal activation of SMC ATPase by intra- and inter-molecular interactions. EMBO J 20, 3238-3250.

32. Hirano, T. (2016). Condensin-Based Chromosome Organization from Bacteria to Vertebrates. Cell 164, 847-857.

33. Holm, L. (2020). Using Dali for Protein Structure Comparison. Methods Mol Biol 2112, 29-42.

34. Hopfner, K.P. (2016). Invited review: Architectures and mechanisms of ATP binding cassette proteins. Biopolymers 105, 492-504.

35. Hosp, F., Scheltema, R.A., Eberl, H.C., Kulak, N.A., Keilhauer, E.C., Mayr, K., and Mann, M. (2015). A Double-Barrel Liquid Chromatography-Tandem Mass Spectrometry (LC-MS/MS) System to Quantify 96 Interactomes per Day. Mol Cell Proteomics 14, 20302041.

36. Kabsch, W. (2010). Integration, scaling, space-group assignment and post-refinement. Acta Crystallogr D Biol Crystallogr 66, 133-144.

37. Kanno, T., Berta, D.G., and Sjogren, C. (2015). The Smc5/6 Complex Is an ATP-Dependent Intermolecular DNA Linker. Cell Rep 12, 14711482 .

38. Kegel, A., Betts-Lindroos, H., Kanno, T., Jeppsson, K., Strom, L., Katou, Y., Itoh, T., Shirahige, K., and Sjogren, C. (2011). Chromosome length influences replication-induced topological stress. Nature 471, 392-396.

39. Kim, Y., Shi, Z., Zhang, H., Finkelstein, I.J., and Yu, H. (2019). Human cohesin compacts DNA by loop extrusion. Science 366, 13451349.

40. Kimanius, D., Forsberg, B.O., Scheres, S.H., and Lindahl, E. (2016). Accelerated cryo-EM structure determination with parallelisation using GPUs in RELION-2. Elife 5.

41. Klykov, O., Steigenberger, B., Pektas, S., Fasci, D., Heck, A.J.R., and Scheltema, R.A. (2018). Efficient and robust proteome-wide approaches for cross-linking mass spectrometry. Nat Protoc 13, $2964-$ 2990.

42. Krissinel, E., and Henrick, K. (2007). Inference of macromolecular assemblies from crystalline state. J Mol Biol 372, 774-797.

43. Kschonsak, M., Merkel, F., Bisht, S., Metz, J., Rybin, V., Hassler, M., and Haering, C.H. (2017). Structural Basis for a Safety-Belt Mechanism That Anchors Condensin to Chromosomes. Cell 171, 588-600 e524.
44. Kuchay, S., Wang, H., Marzio, A., Jain, K., Homer, H., Fehrenbacher, N., Philips, M.R., Zheng, N., and Pagano, M. (2019). GGTase3 is a newly identified geranylgeranyltransferase targeting a ubiquitin ligase. Nat Struct Mol Biol 26, 628-636.

45. Lammens, A., Schele, A., and Hopfner, K.P. (2004). Structural biochemistry of ATP-driven dimerization and DNA-stimulated activation of SMC ATPases. Curr Biol 14, 1778-1782.

46. Landau, M., Mayrose, I., Rosenberg, Y., Glaser, F., Martz, E., Pupko, T., and Ben-Tal, N. (2005). ConSurf 2005: the projection of evolutionary conservation scores of residues on protein structures. Nucleic Acids Res 33, W299-302.

47. Lee, B.G., Merkel, F., Allegretti, M., Hassler, M., Cawood, C., Lecomte, L., O’Reilly, F.J., Sinn, L.R., Gutierrez-Escribano, P., Kschonsak, M., et al. (2020). Cryo-EM structures of holo condensin reveal a subunit flip-flop mechanism. Nat Struct Mol Biol 27, 743-751.

48. Lehmann, A.R., Walicka, M., Griffiths, D.J., Murray, J.M., Watts, F.Z., McCready, S., and Carr, A.M. (1995). The rad18 gene of Schizosaccharomyces pombe defines a new subgroup of the SMC superfamily involved in DNA repair. Mol Cell Biol 15, 7067-7080.

49. Leung, G.P., Lee, L., Schmidt, T.I., Shirahige, K., and Kobor, M.S. (2011). Rtt107 is required for recruitment of the SMC5/6 complex to DNA double strand breaks. J Biol Chem 286, 26250-26257.

50. Li, Y., Muir, K.W., Bowler, M.W., Metz, J., Haering, C.H., and Panne, D. (2018). Structural basis for Scc3-dependent cohesin recruitment to chromatin. Elife 7.

51. Litwin, I., Pilarczyk, E., and Wysocki, R. (2018). The Emerging Role of Cohesin in the DNA Damage Response. Genes (Basel) 9.

52. Liu, Y., Sung, S., Kim, Y., Li, F., Gwon, G., Jo, A., Kim, A.K., Kim, T., Song, O.K., Lee, S.E., et al. (2016). ATP-dependent DNA binding, unwinding, and resection by the Mre11/Rad50 complex. EMBO J 35, 743-758.

53. Marcotrigiano, J., Lomakin, I.B., Sonenberg, N., Pestova, T.V., Hellen, C.U., and Burley, S.K. (2001). A conserved HEAT domain within eIF4G directs assembly of the translation initiation machinery. Mol Cell 7, 193-203.

54. McDonald, W.H., Pavlova, Y., Yates, J.R., 3rd, and Boddy, M.N. (2003). Novel essential DNA repair proteins Nse1 and Nse2 are subunits of the fission yeast Smc5-Smc6 complex. J Biol Chem 278, 45460-45467.

55. Nunez, R.V., Polyhach, Y., Soh, Y.-M., Jeschke, G., and Gruber, S. (2021). Gradual opening of Smc arms in prokaryotic condensin. 2021.2001.2021.427566.

56. Olsen, J.V., Macek, B., Lange, O., Makarov, A., Horning, S., and Mann, M. (2007). Higher-energy C-trap dissociation for peptide modification analysis. Nat Methods 4, 709-712.

57. Onoda, F., Takeda, M., Seki, M., Maeda, D., Tajima, J., Ui, A., Yagi, H., and Enomoto, T. (2004). SMC6 is required for MMSinduced interchromosomal and sister chromatid recombinations in Saccharomyces cerevisiae. DNA Repair (Amst) 3, 429-439.

58. Oravcova, M., Gadaleta, M.C., Nie, M., Reubens, M.C., Limbo, O., Russell, P., and Boddy, M.N. (2019). Brc1 Promotes the Focal Accumulation and SUMO Ligase Activity of Smc5-Smc6 during Replication Stress. Mol Cell Biol 39.

59. Palecek, J., Vidot, S., Feng, M., Doherty, A.J., and Lehmann, A.R. (2006). The Smc5-Smc6 DNA repair complex. bridging of the Smc5Smc6 heads by the KLEISIN, Nse4, and non-Kleisin subunits. J Biol Chem 281, 36952-36959.

60. Palecek, J.J., and Gruber, S. (2015). Kite Proteins: a Superfamily of SMC/Kleisin Partners Conserved Across Bacteria, Archaea, and 
Eukaryotes. Structure 23, 2183-2190.

61. Pape, T., and Schneider, T.R. (2004). HKL2MAP: a graphical user interface for macromolecular phasing with SHELX programs. Journal of Applied Crystallography 37, 843-844.

62. Pebernard, S., McDonald, W.H., Pavlova, Y., Yates, J.R., 3rd, and Boddy, M.N. (2004). Nse1, Nse2, and a novel subunit of the Smc5Smc6 complex, Nse3, play a crucial role in meiosis. Mol Biol Cell $15,4866-4876$.

63. Pebernard, S., Perry, J.J., Tainer, J.A., and Boddy, M.N. (2008). Nse1 RING-like domain supports functions of the Smc5-Smc6 holocomplex in genome stability. Mol Biol Cell 19, 4099-4109.

64. Pebernard, S., Wohlschlegel, J., McDonald, W.H., Yates, J.R., 3rd, and Boddy, M.N. (2006). The Nse5-Nse6 dimer mediates DNA repair roles of the Smc5-Smc6 complex. Mol Cell Biol 26, 1617-1630.

65. Peng, X.P., Lim, S., Li, S., Marjavaara, L., Chabes, A., and Zhao, X. (2018). Acute Smc5/6 depletion reveals its primary role in rDNA replication by restraining recombination at fork pausing sites. PLoS Genet 14, e1007129.

66. Petela, N.J., Gligoris, T.G., Metson, J., Lee, B.G., Voulgaris, M., Hu, B., Kikuchi, S., Chapard, C., Chen, W., Rajendra, E., et al. (2018). Scc2 Is a Potent Activator of Cohesin's ATPase that Promotes Loading by Binding Scc1 without Pds5. Mol Cell 70, 1134-1148 e1137.

67. Post, H., Penning, R., Fitzpatrick, M.A., Garrigues, L.B., Wu, W., MacGillavry, H.D., Hoogenraad, C.C., Heck, A.J., and Altelaar, A.F. (2017). Robust, Sensitive, and Automated Phosphopeptide Enrichment Optimized for Low Sample Amounts Applied to Primary Hippocampal Neurons. J Proteome Res 16, 728-737.

68. Potts, P.R., and Yu, H. (2005). Human MMS21/NSE2 is a SUMO ligase required for DNA repair. Mol Cell Biol 25, 7021-7032.

69. Prakash, S., and Prakash, L. (1977). Increased spontaneous mitotic segregation in MMS-sensitive mutants of Saccharomyces cerevisiae. Genetics 87, 229-236.

70. Raschle, M., Smeenk, G., Hansen, R.K., Temu, T., Oka, Y., Hein, M.Y., Nagaraj, N., Long, D.T., Walter, J.C., Hofmann, K., et al. (2015). DNA repair. Proteomics reveals dynamic assembly of repair complexes during bypass of DNA cross-links. Science 348, 1253671.

71. Scheltema, R.A., Hauschild, J.P., Lange, O., Hornburg, D., Denisov, E., Damoc, E., Kuehn, A., Makarov, A., and Mann, M. (2014). The Q Exactive HF, a Benchtop mass spectrometer with a pre-filter, highperformance quadrupole and an ultra-high-field Orbitrap analyzer. Mol Cell Proteomics 13, 3698-3708.

72. Schindelin, J., Arganda-Carreras, I., Frise, E., Kaynig, V., Longair, M., Pietzsch, T., Preibisch, S., Rueden, C., Saalfeld, S., Schmid, B., et al. (2012). Fiji: an open-source platform for biological-image analysis. Nat Methods 9, 676-682.

73. Seifert, F.U., Lammens, K., Stoehr, G., Kessler, B., and Hopfner, K.P. (2016). Structural mechanism of ATP-dependent DNA binding and DNA end bridging by eukaryotic Rad50. EMBO J 35, 759-772.

74. Serrano, D., Cordero, G., Kawamura, R., Sverzhinsky, A., Sarker, M., Roy, S., Malo, C., Pascal, J.M., Marko, J.F., and D'Amours, D. (2020). The Smc5/6 Core Complex Is a Structure-Specific DNA Binding and Compacting Machine. Mol Cell 80, 1025-1038 e1025.

75. Sheldrick, G.M. (2010). Experimental phasing with SHELXC/D/E: combining chain tracing with density modification. Acta Crystallogr D Biol Crystallogr 66, 479-485.

76. Shevchenko, A., Tomas, H., Havlis, J., Olsen, J.V., and Mann, M. (2006). In-gel digestion for mass spectrometric characterization of proteins and proteomes. Nat Protoc 1, 2856-2860.

77. Shi, Z., Gao, H., Bai, X.C., and Yu, H. (2020). Cryo-EM structure of the human cohesin-NIPBL-DNA complex. Science 368, 1454-1459.
78. Soh, Y.M., Burmann, F., Shin, H.C., Oda, T., Jin, K.S., Toseland, C.P., Kim, C., Lee, H., Kim, S.J., Kong, M.S., et al. (2015). Molecular basis for SMC rod formation and its dissolution upon DNA binding. Mol Cell 57, 290-303.

79. Steigenberger, B., Pieters, R.J., Heck, A.J.R., and Scheltema, R.A. (2019). PhoX: An IMAC-Enrichable Cross-Linking Reagent. ACS Cent Sci 5, 1514-1522.

80. Szabo, Q., Bantignies, F., and Cavalli, G. (2019). Principles of genome folding into topologically associating domains. Sci Adv 5, eaaw 1668 .

81. Torres-Rosell, J., Machin, F., and Aragon, L. (2005a). Smc5-Smc6 complex preserves nucleolar integrity in S. cerevisiae. Cell Cycle 4, 868-872.

82. Torres-Rosell, J., Machin, F., Farmer, S., Jarmuz, A., Eydmann, T., Dalgaard, J.Z., and Aragon, L. (2005b). SMC5 and SMC6 genes are required for the segregation of repetitive chromosome regions. Nat Cell Biol 7, 412-419.

83. Torres-Rosell, J., Sunjevaric, I., De Piccoli, G., Sacher, M., EckertBoulet, N., Reid, R., Jentsch, S., Rothstein, R., Aragon, L., and Lisby, M. (2007). The Smc5-Smc6 complex and SUMO modification of Rad52 regulates recombinational repair at the ribosomal gene locus. Nat Cell Biol 9, 923-931.

84. Varejao, N., Ibars, E., Lascorz, J., Colomina, N., Torres-Rosell, J., and Reverter, D. (2018). DNA activates the Nse2/Mms21 SUMO E3 ligase in the Smc5/6 complex. EMBO J 37.

85. Vazquez Nunez, R., Ruiz Avila, L.B., and Gruber, S. (2019). Transient DNA Occupancy of the SMC Interarm Space in Prokaryotic Condensin. Mol Cell 75, 209-223 e206.

86. Vondrova, L., Kolesar, P., Adamus, M., Nociar, M., Oliver, A.W., and Palecek, J.J. (2020). A role of the Nse4 kleisin and Nse1/Nse3 KITE subunits in the ATPase cycle of SMC5/6. Sci Rep 10, 9694.

87. Wan, B., Wu, J., Meng, X., Lei, M., and Zhao, X. (2019). Molecular Basis for Control of Diverse Genome Stability Factors by the MultiBRCT Scaffold Rtt107. Mol Cell 75, 238-251 e235.

88. Wells, J.N., Gligoris, T.G., Nasmyth, K.A., and Marsh, J.A. (2017). Evolution of condensin and cohesin complexes driven by replacement of Kite by Hawk proteins. Curr Biol 27, R17-R18.

89. Wilhelm, L., Burmann, F., Minnen, A., Shin, H.C., Toseland, C.P., Oh, B.H., and Gruber, S. (2015). SMC condensin entraps chromosomal DNA by an ATP hydrolysis dependent loading mechanism in Bacillus subtilis. Elife 4.

90. Xaver, M., Huang, L., Chen, D., and Klein, F. (2013). Smc5/6-Mms21 prevents and eliminates inappropriate recombination intermediates in meiosis. PLoS Genet 9, e1004067.

91. Yatskevich, S., Rhodes, J., and Nasmyth, K. (2019). Organization of Chromosomal DNA by SMC Complexes. Annu Rev Genet 53, 445-482.

92. Yu, Y., Li, S., Ser, Z., Sanyal, T., Choi, K., Wan, B., Sali, A., Kentsis, A., Patel, D.J., and Zhao, X. (2021). Integrative analysis reveals unique features of the Smc5/6 complex. 2020.2012.2031.424863.

93. Zabrady, K., Adamus, M., Vondrova, L., Liao, C., Skoupilova, H., Novakova, M., Jurcisinova, L., Alt, A., Oliver, A.W., Lehmann, A.R., et al. (2016). Chromatin association of the SMC5/6 complex is dependent on binding of its NSE3 subunit to DNA. Nucleic Acids Res 44, 1064-1079.

94. Zhang, K. (2016). Gctf: Real-time CTF determination and correction. J Struct Biol 193, 1-12.

95. Zhao, X., and Blobel, G. (2005). A SUMO ligase is part of a nuclear multiprotein complex that affects DNA repair and chromosomal organization. Proc Natl Acad Sci U S A 102, 4777-4782. 
bioRxiv preprint doi: https://doi.org/10.1101/2021.02.09.430422; this version posted February 9,2021. The copyright holder for this preprint

(which was not certified by peer review) is the author/funder, who has granted bioRxiv a license to display the preprint in perpetuity. It is made available under aCC-BY 4.0 International license.

96. Zheng, S.Q., Palovcak, E., Armache, J.P., Verba, K.A., Cheng, Y., and Agard, D.A. (2017). MotionCor2: anisotropic correction of beaminduced motion for improved cryo-electron microscopy. Nat Methods 14, 331-332.

97. Zivanov, J., Nakane, T., Forsberg, B.O., Kimanius, D., Hagen, W.J., Lindahl, E., and Scheres, S.H. (2018). New tools for automated high-resolution cryo-EM structure determination in RELION-3. Elife 7. 